\title{
A design approach for multiple drive belt conveyors minimizing life cycle costs
}

\author{
Mukalu Sandro Masaki, Lijun Zhang*, Xiaohua Xia \\ Department of Electrical, Electronic and Computer Engineering, University of Pretoria, Pretoria 0002, South Africa
}

\begin{abstract}
Energy efficiency of belt conveyors has recently gained in importance worldwide. While significant research efforts were consecrated to the operational aspects, the literature study shows the design optimization problem was scarcely investigated in the past. Among the various type of belt conveyors, the multi-drive technology is now increasingly acknowledged as involving further cost saving opportunities as a result of the possible reduction of the belt weight. In this paper, a multi-drive belt conveyor sizing model that aims to minimize the life cycle cost of the conveyor is presented. The effectiveness of the proposed approach in improving their economic benefits over the single-drive conveyors has been established through extensive simulations on a practical case study. The robustness of the best design solution against the variation in the inflation rate have been also validated.
\end{abstract}

Keywords: Belt conveyor, life cycle cost, multiple drive, optimal design, component sizing, energy management.

\section{Introduction}

Energy shortage is a major concern to many countries around the world. With $83 \%$ of electricity generated by coal-fired power plants [1], statistics from the largest South African energy company, Eskom, indicated that while the entire mining sector consumed $15 \%$ of its annual electricity supply, approximately $23 \%$ of this consumption was used for material transportation purposes only [2]. Amongst the existing technologies, belt conveyors are largely used for bulk material transfer over short and medium distances because of their low energy consumption per tonne of material transported in comparison to other alternatives $[3,4,5]$. A significant number of belt conveyors are, however, either oversized or inadequately operated, resulting in poor energy efficiency and economic performances $[6,3,7]$. As a result, any improvement in energy efficiency achieved at the design or operation stage of a conveyor can reduce its capital investment and/or operating expenditures.

Generally, energy efficiency activities can be clustered into four categories, namely initiatives focusing on technology, operation, equipment, and performance efficiencies $[8,9,10]$. With indicators such as feasibility, life cycle cost, and return on investment, technology efficiency refers to the efficiencies of energy conversion, processing, transmission, and usage. Equipment efficiency is a measure of the energy output of isolated individual equipment with respect to given technology design specifications. Typical indicators include capacity and maintenance. Operation efficiency focuses on the degree of coordination of the different components of an energy system. Physical coordination, time coordination and human coordination are the indicators usually considered at this level. Performance efficiency is a measure of the global efficiency of the energy system, and is evaluated by external but deterministic indicators such as the production, cost, and environmental footprint. Readers interested in more detailed definitions of technology, operation, equipment, and performance efficiencies are referred to reference [8].

Findings from the literature indicate that most of the previous efforts to improve belt conveyor's energy efficiency were done at the equipment level, operation level, and technology level. Equipment efficiency

\footnotetext{
${ }^{*}$ Corresponding author. Tel: +27012 4202674.

Email address: lijun.zhang@up.ac.za (Lijun Zhang)

Postprint submitted to Journal of Cleaner Production
}

August 2, 2018 


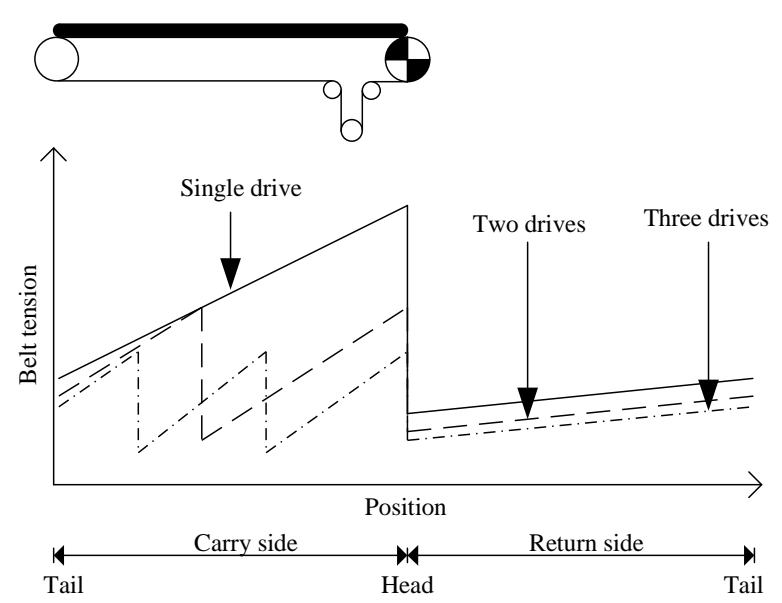

Figure 1: Belt tension profile v.s. number of driving stations (adapted from [32])

activities include the development of energy-efficient belting materials [11, 12], application of energy-efficient motors and variable speed drives [13], and monitoring and maintenance of conveyor components based on risks of failure and expert system tools $[14,15]$. At the operation efficiency level, initiatives include costeffective load shifting [16], adaptive belt speed control [17, 18, 19], material scheduling under the time-of-use electricity tariff $[3,20,21]$ and critical peak pricing [22], and the optimal power flow between the electric drives [23]. The impacts of the settings of certain design parameters on the future power consumption of a belt conveyor were also investigated [24]. Technology efficiency activities involve strategies for selecting idler rolls [25], advanced design of troughing idler sets [4, 26], and modelling of motion resistance components $[27,28,29]$.

In practice, for a given transportation task, different designs of belt conveyor will usually result in different cost implications regarding both investment and operation expenditures. Possibilities to minimize the entire life cycle cost through the optimal dimensioning of belt conveyor components were reported in the literature for single drive conveyor belts [30,31]. Belt conveyors using multiple drive design were, however, not covered in the studies previously reported.

Since the early applications in the United States and Germany in the seventies, the distributed drive technology has today reached maturity. Multiple drive conveyor systems are already widely used in underground coal mines and are increasingly being considered in the mining plan for future developments [32]. Fig. 1 illustrates the evolution of the belt tension profile before and after one, and subsequently, two drive stations are inserted in the upper stretch of a single drive conveyor. The decline of the maximum belt tension achieved by increasing the number of intermediate drive stations may allow conveyor designers to shift towards less resistant belt products and thereby reducing the weight of the belt and the supporting structure.

The resulting economic benefit of this practice is, however, subject to the interactions between the various design parameters relevant to the capital and operational costs of the belt conveyor components. In particular, to achieve good performance for a specified transportation task, the number of drive stations should be set taking into account the influence of their respective sizes and distribution along the belt path, and the belt speed, among others. To the best of the authors' knowledge, no previous study dedicated to the economic design of multiple drive belt conveyors was reported in the literature. The rest of this paper presents a contribution on the cost-effective component sizing model for multiple drive belt conveyors. The proposed approach intends to optimally determine the most important design parameters in order to minimize the life cycle cost of such a conveyor system while satisfying various design and operational constraints. This introduces a method for economic design of multi-drive conveyors for plant owners to make the best use of capital investments and to reduce operating cost of the belt conveyors. In particular, solution of the presented model yields the optimal sizes of components of a multi-drive conveyor that will result in the minimum capital and operating costs over the entire lifespan of the conveyor subject to design constraints. Therefore, the model developed will be a handy and powerful tool to help plant owners to 
design the most cost-effective conveyor solutions to their needs. It can also be used as a decision support tool for plant owners when comparing different investment options for material transportation using belt conveyors.

The rest of this paper is organized as follows. A brief introduction to multi-drive belt conveyor is given in Section 2. The cost-effective design problem for multi-drive conveyors is formulated in Section 3, followed by the detailed mathematical modeling of the belt conveyor in Section 4 . Section 5 presents a case study to demonstrate the effectiveness of the optimal component sizing model developed. The robustness of the cost-effective conveyor designs against possible fluctuations in the inflation rate during the project is also discussed. Section 6 concludes this study.

\begin{tabular}{|c|c|}
\hline \multicolumn{2}{|c|}{ Nomenclature } \\
\hline$\alpha_{i}$ & Wrap angle of drive pulleys in the $i$-th drive station $\left[^{\circ}\right]$ \\
\hline$\beta$ & Equivalent angle of slope of the material $\left[^{\circ}\right]$ \\
\hline$\gamma_{\text {belt }}$ & Specific mass of the belt $\left[\mathrm{kg} / \mathrm{m}^{2}\right]$ \\
\hline$\delta_{j}$ & Inclination angle of the belt section $j\left[^{\circ}\right]$ \\
\hline$\eta_{\text {gear }, i}$ & Efficiency of gear reducers in the $i$-th drive station \\
\hline$\eta_{m o t, i}$ & Efficiency of motors in the $i$-th drive station \\
\hline$\lambda$ & Troughing angle $\left[^{\circ}\right]$ \\
\hline$\mu$ & Friction factor between the drive pulley and the conveyor belt \\
\hline$\mu_{1}$ & Friction factor between belt and material conveyed \\
\hline$\mu_{2}$ & Friction factor between the lateral chutes and the material transferred \\
\hline$\mu_{3}$ & Friction factor between the belt cleaning device and the belt \\
\hline$\xi_{o}$ & Number of idler rolls per set on the carry side \\
\hline$\xi_{u}$ & Number of idler rolls per set on the return side \\
\hline$\rho$ & Material density $\left[\mathrm{kg} / \mathrm{m}^{3}\right]$ \\
\hline$a$ & Constant factor for the calculation of clear width of lateral chutes \\
\hline$A_{G r}$ & Effective contact area between belt cleaning device and belt $\left[\mathrm{m}^{2}\right]$ \\
\hline$A_{t h}$ & Theoretical cross section of fill $\left[\mathrm{m}^{2}\right]$ \\
\hline$A_{\text {conveyor }}$ & Annual equivalent cost of the belt conveyor [USD/year] \\
\hline$A_{\text {belt }}$ & Annual equivalent cost of the belt [USD/year] \\
\hline$A_{\text {carryidler }}$ & Annual equivalent cost of all the carry idler rolls [USD/year] \\
\hline$A_{\text {energy }}$ & Annual equivalent energy cost [USD/year] \\
\hline$A_{e q}$ & Annual equivalent cost of an equipment [USD/year] \\
\hline$A_{\text {gear }, i}$ & Annual equivalent cost of each gear reducer in the $i$-th drive station [USD/year] \\
\hline$A_{\text {motor }, i}$ & Annual equivalent cost of each motor in the $i$-th drive station [USD/year] \\
\hline$j$ & Belt section index \\
\hline$A_{\text {returnidler }}$ & Annual equivalent cost of all the return idler rolls [USD/year] \\
\hline$B$ & Belt width $[\mathrm{m}]$ \\
\hline $\mathfrak{B}$ & Set of the recommended width of belt \\
\hline$b$ & Usable belt width $[\mathrm{m}]$ \\
\hline$B_{f}$ & Dynamic load factor related to bearing life \\
\hline$b_{\text {Sch }}$ & Clear width of lateral chutes $[\mathrm{m}]$ \\
\hline$C_{e q, 0}$ & First cost of the item of an equipment purchased at the year zero [USD] \\
\hline$C_{f}$ & Belt flap factor \\
\hline$C_{\text {Rank }}$ & Rakine coefficient \\
\hline$C_{S c h b}$ & $\begin{array}{l}\text { Constant factor for additional resistance between material transferred and lateral } \\
\text { chutes }\end{array}$ \\
\hline$c_{T r}$ & $\begin{array}{l}\text { Drive pulleys constant coefficient related to the type longitudinal tension members } \\
\text { of the belt }\end{array}$ \\
\hline$C_{w, i}$ & Combined warp factor of the drive pulleys in the $i$-th drive station \\
\hline$c_{1}, \ldots, c_{22}$ & Initial cost coefficients \\
\hline $\mathfrak{D}$ & Set of the recommended diameters of idler roll \\
\hline
\end{tabular}




\begin{tabular}{|c|c|}
\hline $\mathfrak{d}$ & Set of the recommended shaft diameters of idler roll \\
\hline $\mathfrak{D}_{t r}$ & Set of the recommended diameters of drive pulley \\
\hline$d_{G k}$ & Thickness of the longitudinal tension members of the belt $[\mathrm{m}]$ \\
\hline$D_{j}$ & Diameter of idler rolls in the belt section $j[\mathrm{~m}]$ \\
\hline$d_{j}$ & Shaft diameter of idler rolls in the belt section $j[\mathrm{~m}]$ \\
\hline$D_{o}$ & Diameter of idler rolls in the upper stretch $[\mathrm{m}]$ \\
\hline$d_{o}$ & Shaft diameter of idler rolls in the upper stretch $[\mathrm{m}]$ \\
\hline$D_{u}$ & Diameter of idler rolls in the lower stretch [m] \\
\hline$d_{u}$ & Shaft diameter of idler rolls in the lower stretch $[\mathrm{m}]$ \\
\hline$e_{o}$ & Unit cost of energy at the year zero of the project [USD/kWh] \\
\hline$f_{j}$ & Hypothetical friction factor in the belt section $j$ \\
\hline$F_{A u f, j}$ & $\begin{array}{l}\text { Resistance due to the acceleration of the material in the loading zone of the belt } \\
\text { section } j[\mathrm{~N}]\end{array}$ \\
\hline$F_{\min }$ & Minimum belt tension in steady-state operating conditions $[\mathrm{N}]$ \\
\hline$F_{G, j}$ & Gradient resistance in the belt section $j[\mathrm{~N}]$ \\
\hline$F_{G r, j}$ & frictional resistance due to belt cleaning devices situated in the belt section $j[\mathrm{~N}]$ \\
\hline$F_{H, j}$ & Primary resistance in the belt section $j[\mathrm{~N}]$ \\
\hline$F_{0}$ & Belt tension at each side of the tail pulley $[\mathrm{N}]$ \\
\hline$F_{N, j}$ & Secondary resistance in the belt section $j[\mathrm{~N}]$ \\
\hline$F_{S, j}$ & Special resistance in the belt section $j[\mathrm{~N}]$ \\
\hline$F_{s, o}$ & Static load on the central carry idler roll in a three-idler troughing configuration $[\mathrm{N}]$ \\
\hline$F_{s, u}$ & Static load on a flat return idler in the lower stretch $[\mathrm{N}]$ \\
\hline$F_{S c h b, j}$ & $\begin{array}{l}\text { frictional resistance between belt and lateral chutes in the acceleration zone of the } \\
\text { belt section } j[\mathrm{~N}]\end{array}$ \\
\hline$F_{T 1, i}$ & Tight side tension of the first drive pulley in the $i$-th drive station $[\mathrm{N}]$ \\
\hline$F_{T 2, i}$ & Slack side tension of the second drive pulley in the $i$-th drive station $[\mathrm{N}]$ \\
\hline$F_{T U}$ & Belt tension on both sides of the take-up device $[\mathrm{N}]$ \\
\hline$F_{W, j}$ & Total resistance to movement in the belt section $j[\mathrm{~N}]$ \\
\hline$F_{0}$ & Belt tension at the conveyor tail $[\mathrm{N}]$ \\
\hline$g$ & Gravitational acceleration $\left[\mathrm{m} / \mathrm{s}^{2}\right]$ \\
\hline$H$ & Lifting height $[\mathrm{m}]$ \\
\hline$h_{r e l}$ & Maximum belt sag related to spacing between idler rolls \\
\hline$i$ & Integer index \\
\hline$i_{d}$ & Interest rate on debt \\
\hline$i_{e}$ & After-tax return required on equity funds with zero inflation rate \\
\hline$i_{f, j}$ & Inflation modified rate of return of the year $j$ of the project \\
\hline$i_{f}^{0}$ & $\begin{array}{l}\text { Time value of money with all cash flows converted from inflated value to constant } \\
\text { year zero value }\end{array}$ \\
\hline$j$ & Integer index \\
\hline$K$ & Total length of the belt along the conveyor path $[\mathrm{m}]$ \\
\hline$k_{b}$ & Constant factor for calculation of the total length of the acceleration path \\
\hline$k_{N}$ & Nominal breaking strength of the belt related to belt width $[\mathrm{N} / \mathrm{m}]$ \\
\hline$k_{e q}$ & Equivalent annual cost coefficient of an equipment \\
\hline$k_{t, r e l}$ & Relative reference endurance strength of the belt \\
\hline$k_{1}, \ldots, k_{6}$ & Equivalent annual cost coefficients \\
\hline$L$ & Horizontal transport distance $[\mathrm{m}]$ \\
\hline$l_{b}$ & Total length of the acceleration path $[\mathrm{m}]$ \\
\hline$L_{f}$ & Dynamic load factor related to lump size of the material transferred \\
\hline$l_{j}$ & Length of the belt section $j[\mathrm{~m}]$ \\
\hline$L_{o, j}$ & Length of the belt section $j$ in the upper stretch $[\mathrm{m}]$ \\
\hline$l_{M, o}$ & Length of the shell of a carry idler roll $[\mathrm{m}]$ \\
\hline
\end{tabular}




\begin{tabular}{|c|c|}
\hline$l_{o}$ & Spacing between idler rolls in the upper stretch $[\mathrm{m}]$ \\
\hline$L_{u, j}$ & Length of the belt section $j$ in the lower stretch [m] \\
\hline$l_{u}$ & Spacing between idler rolls in the lower stretch [m] \\
\hline$M$ & Expected lifetime of each item of an equipment [year] \\
\hline$m_{G}^{\prime}$ & Linear mass of the belt $[\mathrm{kg} / \mathrm{m}]$ \\
\hline$m_{L, j}^{\prime}$ & Linear mass of the transferred material in the belt section $j[\mathrm{~kg} / \mathrm{m}]$ \\
\hline$m_{R, j}$ & Mass of the rotating parts of each idler situated in the belt section $j[\mathrm{~kg}]$ \\
\hline$m_{R, j}^{\prime}$ & $\begin{array}{l}\text { Linear mass of the rotating parts of idlers per running meter in the belt section } j \\
{[\mathrm{~kg} / \mathrm{m}]}\end{array}$ \\
\hline$m_{1}$ & Belt weight model coefficient $\left[\mathrm{kg} / \mathrm{m}^{2}\right]$ \\
\hline$m_{2}$ & Belt weight model coefficient $\left[\mathrm{s}^{2} / \mathrm{m}^{2}\right]$ \\
\hline$m_{3}$ & Steelcord diameter model coefficient $[\mathrm{m}]$ \\
\hline$m_{4}$ & Steelcord diameter model coefficient $[\mathrm{m}]$ \\
\hline$m_{5}$ & Steelcord diameter model coefficient $[\mathrm{m}]$ \\
\hline$N$ & Number of intermediate drive stations \\
\hline$N_{o}$ & Number of belt sections in the upper stretch \\
\hline$N_{u}$ & Number of belt sections in the lower stretch \\
\hline$n_{1}$ & Dynamic speed load factor model coefficient \\
\hline$n_{2}$ & Dynamic speed load factor model coefficient $[\mathrm{s} / \mathrm{m}]$ \\
\hline$o$ & Upper stretch \\
\hline$P_{i}$ & Rated power of motors in the $i$-th drive station $[\mathrm{kW}]$ \\
\hline$P E D_{e q}$ & Present equivalent of depreciation of the items of an equipment [USD] \\
\hline$P E F_{e q}$ & Present equivalent of all the first cost of an equipment [USD] \\
\hline$P E V_{e q}$ & Present equivalent of all the salvage value of an equipment [USD] \\
\hline$p_{G r}$ & Pressure between the belt cleaning device and the belt $\left[\mathrm{N} / \mathrm{m}^{2}\right]$ \\
\hline$Q$ & Material flow rate $[\mathrm{kg} / \mathrm{s}]$ \\
\hline$q_{f}$ & $\begin{array}{l}\text { Remaining proportion of the initial value of an equipment at the end of the expected } \\
\text { lifetime }\end{array}$ \\
\hline$q_{i}$ & $\begin{array}{l}\text { Remaining proportion of the initial value of the item } i \text { of an equipment at the end } \\
\text { of its actual lifetime }\end{array}$ \\
\hline$R$ & Number of items of an equipment to be purchased over the project lifetime \\
\hline$r_{\text {avg }}$ & Average general inflation rate over the project duration \\
\hline$r_{d}$ & Proportion of debt capital \\
\hline$r_{e, j}$ & Annual escalation rate of energy during the year $j$ \\
\hline$r_{e q, j}$ & Annual cost escalation rate of an equipment during the year $j$ \\
\hline$r_{j}$ & General inflation rate during the year $j$ \\
\hline$S_{f}$ & Dynamic load factor related to belt speed \\
\hline$S_{0}$ & Belt safety factor related to the splicing conditions \\
\hline$S_{1}$ & Belt safety factor related to the expected lifetime and the operation conditions \\
\hline$t$ & Income tax rate \\
\hline$t_{a}$ & Operating hours per annum $[\mathrm{h}]$ \\
\hline$T_{i}$ & Rated torque of gear reducers in the $i$-th drive station $[\mathrm{kNm}]$ \\
\hline$u$ & Lower stretch \\
\hline$v$ & Conveyor speed $[\mathrm{m} / \mathrm{s}]$ \\
\hline$v_{0, j}$ & Initial speed of the material in the direction of belt travel in the belt section $j[\mathrm{~m} / \mathrm{s}]$ \\
\hline$w$ & Width of the contact area between belt and belt cleaning device $[\mathrm{m}]$ \\
\hline$X_{i}$ & Purchase year of the item $i$ of an equipment \\
\hline$Y_{i}$ & Year of decommissioning of the item $i$ of an equipment \\
\hline$y_{1}, y_{2}$ & Belt length model coefficients [m] \\
\hline$Z$ & Project lifetime [year] \\
\hline
\end{tabular}




\section{Description of multi-drive belt conveyors}

Fig. 2 illustrates a typical modern uphill multi-drive belt conveyor that aims to transfer a bulk material of density $\rho$ with a flow rate $Q$ over a distance $L$ with a lift height $H$. It consists basically of an upper stretch and a lower stretch subsequently identified by the subscripts $o$ and $u$, respectively. The upper stretch carries the bulk material from the loading point situated at the tail pulley and along the conveyor path to the unloading points positioned along the conveyor path and at the head pulley. On the other hand, the lower stretch consists of the empty belt that circulates from the head pulley to the tail pulley. Apart from these two pulleys, one or several pairs of drive pulleys mounted in tandem are positioned along the upper stretch of the conveyor. One pair of drive pulleys and one pair of idler pulleys are positioned in the lower stretch as indicated in Fig. 2. Each drive pulley is connected to a motor-gear reducer system mounted at its shaft. The rest of pulleys rotate freely and are driven by the belt. The arc of contact between the belt and a drive pulley is referred to as the wrap angle and is denoted by $\alpha$.

The drive station is the unit comprising a pair of drive pulleys mounted in tandem together with their associated motor-gear reducer systems. In particular, the drive stations situated in the upper stretch are identified as intermediate drive stations. Within a drive station, the drive pulley 1 and drive pulley 2 refer to, respectively, the first and second pulleys when following the belt travel direction in Fig. 2. For illustration purposes, Fig. 2 shows a conveyor system comprising 4 drive stations including 3 intermediate drive stations. A general design will comprise $N+1(N=1,2, \ldots)$ drive stations with $N$ positioned as intermediate drive stations. These drive stations will then be numbered from 1 to $N+1$ starting at the drive station near the tail pulley and ending at the drive station located in the lower stretch.

A belt section refers any portion of belt nestled between any two different pulleys. Like in standard DIN 22101 [33], within each stretch, the edges of each belt section is identified by means of a unique index specified in ascending order starting at the tail pulley identified by default as edge 0 . A belt section is subsequently designated by the greatest index between its two edges. For example, the belt conveyor in Fig. 2 has 7 belt sections in the upper stretch and 5 belt sections in the lower stretch. The belt sections 3 in the upper and lower stretches of the conveyor are also pointed out ig. 2. In more general case, the number $N_{o}$ of belt sections in the upper stretch will depend on $N$, while the number $N_{u}$ of belt sections in the lower stretch will be determined by the number of pairs of idler pulleys installed. Although the number of idler pulleys can vary from one conveyor system to another, this study only considers multi-drive belt conveyors with a single pair of idler pulleys. $N_{u}$ will be therefore equal to 5 in the following. Thereafter, $L_{o, i}$ and $L_{u, j}$ will denote the lengths of, respectively, the belt section $i$ in the upper stretch and the belt section $j$ in the lower stretch.

For the purpose of supporting the belt sections that extend over long distances, carrying and return idler rolls are mounted underneath the belt in these belt sections as described in Fig. 2. Fig. 3(a) also shows the carrying idler rolls also supporting the bulk material in transit along the belt conveyor in the case of

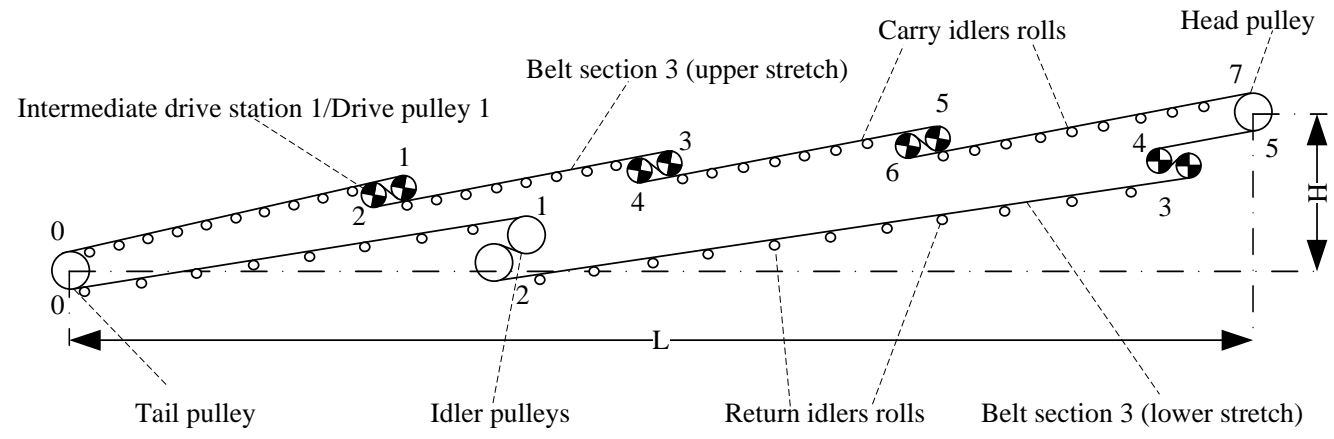

Figure 2: Multiple drive belt conveyor layout (adapted from [32]) 


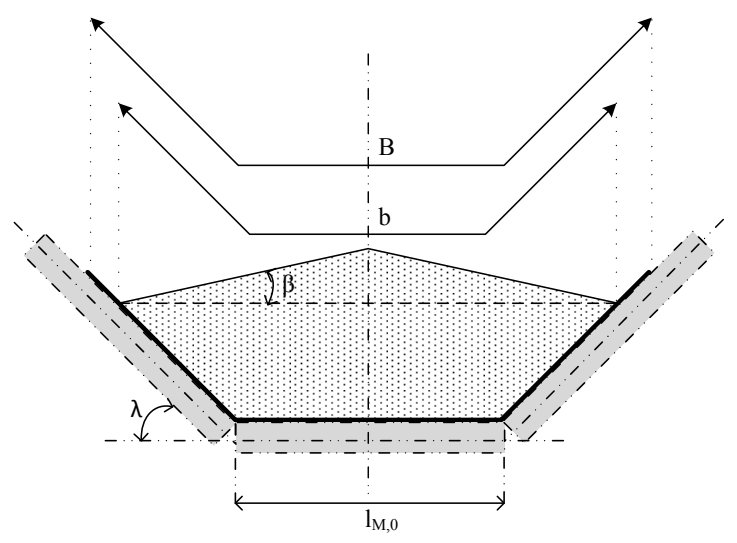

(a) Theoretical cross section of fill

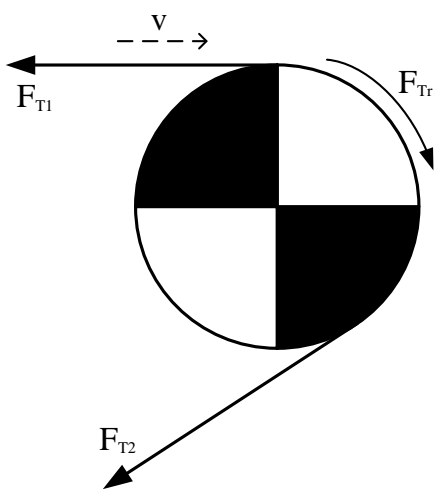

(b) Belt tensions around a drive pulley

Figure 3: Cross section of fill and mechanic around the drive pulley

a three-idler roll troughing configuration. In this figure, $B$ denotes the belt width, $b$ denotes the usable belt width, $\beta$ denotes the equivalent angle of slope of the material, $\lambda$ denotes the troughing angle and $l_{M, o}$ denotes the length of the shell of a carry idler roll.

The resultant longitudinal force measured at a specific point along the conveyor path is referred to as the belt tension at this point and is noted by F. Fig. 3(b) shows the belt tension components around a drive pulley. The belt tension at the belt run-on point on the drive pulley is referred to as the tight side tension, and is noted $F_{T 1}$. On the other side, the belt tension at the belt run-off point on the drive pulley is referred to as the slack side tension, and is noted $F_{T 2}$. Moreover, $F_{T r}$ denotes the peripheral force applied by the drive pulley on the belt. Analogously, $F_{T 1, i}, F_{T 2, i}$ and $F_{T r, i}$ will denote, respectively, the tight side tension, the slack side tension and the peripheral force of the $i$-th drive station. The belt strength is specified by the nominal breaking strength of the belt related to belt width, $k_{N}$, which corresponds to the minimum rupture force of the belt per unit of belt width. Lastly, long belt conveyors usually require to be fitted with a tensioning equipment also referred to as take-up device (not shown in Fig. 2) so as to prevent belt slipping on drive pulleys. The belt tension on each side of the take-up device is noted $F_{T U}$.

\section{Problem formulation}

A given conveying operation can be described by $L, H, Q, \rho$ and $\beta$. For such a material transfer task, a large variety of multi-drive belt conveyors can be envisaged, designs of which will generally lead to different cost implications over the project lifetime. The goal is therefore to identify the design solution that results in the lowest life cycle cost. To facilitate the comparison of belt conveyor designs, the equivalent annual cost of a belt conveyor $A_{\text {conveyor }}$ is adopted as the performance indicator instead of directly inspecting the life cycle costs.

Therefore for a given $N$, the general formulation of the optimization problem that allows to determine the design solution with the minimum $A_{\text {conveyor }}$ is stated as

$$
\begin{array}{cl}
\min _{X} & A_{\text {conveyor }} \\
\text { s.t. } & G(X)=0, \\
& H(X) \geq 0,
\end{array}
$$

where $X$ denotes the set of design parameters and $G$ and $H$ denote, respectively, the functions of equality and inequality constraints relating to the belt dynamics and design conditions as detailed in subsection 4.3. Although $N$ can be treated as a decision variable, it adds much complexity of the model. The direct comparison of the minimum $A_{\text {conveyor }}$ obtained for different $N$ will therefore lead to the most cost-effective design solution in terms of $N$ and $X$.

By keeping the two driving subsystems of each $i$-th drive station $(i=1, \ldots, N+1)$ identical in all respects, the set $X$ considered in this study includes: the rated power of each motor in the $i$-th drive station 
$P_{i}$, the rated torque of each gear reducer in the $i$-th drive station $T_{i}$; the diameter of each drive pulley in the $i$-th drive station $D_{t r, i}$; the wrap angle of each drive pulley in the $i$-th drive station $\alpha_{i} ; L_{o, j}$ of the belt sections $j\left(j=1,3, \ldots, N_{o}\right)$ not nestled between drive pulleys, the belt width, $B$, the belt speed, $v$, the spacing between idler rolls in the upper stretch, $l_{o}$, the spacing between idler rolls in the lower stretch, $l_{u}$, the diameter of idler rolls in the upper stretch, $D_{o}$, the diameter of idler rolls in the lower stretch, $D_{u}$, the shaft diameter of idler rolls in the upper stretch, $d_{o}$, the shaft diameter of idler rolls in the lower stretch, $d_{u}, k_{N}$ and $F_{T U}$.

Regarding the calculation of $A_{\text {conveyor }}$, the various costs incurred throughout the belt conveyor lifetime can be grouped into capital costs and operating costs. Since each of these categories comprises several expense items incurred at different points of time during the project life, $A_{\text {conveyor }}$ will therefore consist of the sum of the equivalent annual costs of each cost item involved. The next subsections give a brief discussion of the cost items relating to the type of belt conveyor investigated in this study.

\subsection{Operating costs}

The operating costs of a belt conveyor include energy cost, maintenance cost and labor cost. While the relationships between the design parameters and the expenditures for maintenance and labor were not investigated in the past, it can be expected that the number and size of drive stations, the conveyor speed and belt size will influence the maintenance cost. On the other hand, the wage and number of workers in a mine are usually driven by the plant size, the production, and the local legislation [5, 30]. Accordingly, no influence on the labor is expected from the design parameters selected in this study. As a result of the difficulties experienced in accessing modelling data for the maintenance part, only with the energy cost is subsequently considered.

The equivalent annual energy cost $A_{\text {energy }}$ of a multi-drive belt conveyor with $N$ intermediate drive stations, with each drive station consisted of two drive pulleys and driving systems, is given by:

$$
A_{\text {energy }}=k_{1} e_{o} t_{a} \sum_{i=1}^{N+1} 2 P_{i} / \eta_{m o t}, i
$$

where $k_{1}$ denotes the equivalent annual energy cost coefficient, $e_{o}$ denotes the unit cost of energy at the year zero of the project, $t_{a}$ denotes the operating hours per annum, and $\eta_{m o t, i}$ denotes the efficiency of motors of the $i$-th drive station. As detailed in Appendix A.1, the calculation of $k_{1}$ takes into account of several factors, including the general inflation rate, the annual escalation rate of energy during the project and the tax rate.

\subsection{Capital costs}

The capital costs of the conveyor components, including the belting material, the electric motors, the gear reducers, the carry idlers and the return idlers, are considered at this stage. Although, in practice, the cost for the supporting structure is significant among the conveyor components, it is not investigated because of its high dependency on the geographic characteristics of the mine.

The initial cost function of belt conveyor components considered in this study is derived from [30, 31]. Further analysis on idler roller purchase costs indicated that the shaft diameter affects the product price in addition to the idler roller's diameter and length. The cost functions of these items were revised accordingly. As a result, the annual equivalent cost of the conveyor components are given as follows 


$$
\begin{gathered}
A_{\text {belt }}=k_{2} B K\left(c_{1}+c_{2} k_{N}^{c_{3}}\right), \\
A_{\text {motor }, i}=k_{3}\left(c_{4}+c_{5} P_{i}^{c_{6}}\right), \\
A_{\text {gear }, i}=k_{4}\left(c_{7}+c_{8} T_{i}^{c_{9}}\right), \\
A_{\text {carryidler }}=\xi_{o} k_{5} \sum_{j=1}^{N_{o}} \frac{L_{o, j}}{l_{o}}\left(c_{10}+c_{11} d_{o}^{c_{12}}+c_{13} D_{o}^{c_{14}}+c_{15} B^{c_{16}}\right), \\
A_{\text {returnidler }}=\xi_{u} k_{6} \sum_{j=1}^{N_{u}} \frac{L_{u, j}}{l_{u}}\left(c_{17}+c_{18} d_{u}^{c_{19}}+c_{20} D_{u}^{c_{21}}+c_{22} B^{c_{23}}\right) .
\end{gathered}
$$

where $K$ denotes the total length of the belt along the conveyor path, $k_{2}$ to $k_{6}$ denote the equivalent annual cost coefficients of belt conveyor components $c_{1}$ to $c_{23}$ denote the initial cost coefficients, $\xi_{o}$ denotes the number of carry idler rolls per set (e.g. $\xi_{o}=3$ a three-idler troughing configuration), and $\xi_{u}$ denotes the number of return idler rolls per set (e.g. $\xi_{u}=1$ in a flat return configuration).

The values of $c_{1}$ to $c_{23}$ are determined based on suppliers' price data. Besides the economic parameters relevant to $k_{1}$, the calculation of the equivalent annual cost coefficient of a given belt conveyor component implies taking into account also the annual escalation rate of the initial costs of this equipment, the first costs of the first item and its replacements purchased during the project life, their related expected lifetimes, their respective annual depreciation rates and their respective salvage values. $k_{2}$ to $k_{6}$ are obtained using the procedure disclosed in Appendix A.2. For its part, $K$ in equation (2) can be approximated by

$$
K=2 L / \cos \delta+y_{1} N+y_{2},
$$

where $\delta$ denotes the inclination angle of the conveyor system, $y_{1}$ and $y_{2}$ denote constant coefficients that account for, respectively, the wrapping of the belt around the drive pulleys and a reserve factor.

The equivalent annual cost of a multiple drive belt conveyor with $N$ intermediate drive stations is therefore given by

$$
A_{\text {conveyor }}=A_{\text {energy }}+A_{\text {belt }}+2 \sum_{i=1}^{N+1} A_{\text {motor }, i}+2 \sum_{i=1}^{N+1} A_{\text {gear }, i}+A_{\text {carryidler }}+A_{\text {returnidler }} .
$$

The cost of the conveyor, $A_{\text {conveyor }}$, varies as a function of the design parameters of the components that form parts of the system. The system design must also accommodate any technical requirements relevant to the technology and the intended application. A multi-drive belt conveyor sizing model that aims to minimize the life cycle of the conveyor is developed in Section 4.

\section{Mathematical model of the multi-drive belt conveyors}

The force analysis, the power balance requirement, and the operational constraints that should be satisfied to ensure the proper and safe operation of the multi-drive belt conveyor are presented in this section.

\subsection{Motion resistance modelling}

According to DIN 22101 standard [33], the overall resistance to the belt movement $F_{W, j}$ that occurs within a belt section $j$ consists of the primary resistance, the secondary resistance, the gradient resistance and the special resistance.

The primary resistance $F_{H, j}$ combines together the running resistance forces caused by indentation of the belt cover on the idler rolls, the flexure of the belt between the idler rolls, and the rotational resistance of idler rolls. The resulting opposition force to the belt movement in the section $j$ is approximated by:

$$
\left.F_{H, j}=l_{j} f_{j}\left[m_{R, j}^{\prime}+{ }_{9}^{m_{G}^{\prime}}+m_{L, j}^{\prime}\right) \cos \delta_{j}\right] g,
$$


where $l_{j}$ denotes the length of the belt section, $f_{j}$ denotes the hypothetical friction factor, $g$ denotes the gravitational acceleration, $m_{R, j}^{\prime}$ denotes the total mass of the rotating parts of idler rolls per running meter, $m_{G}^{\prime}$ denotes the linear mass of the belt, $m_{L, j}^{\prime}$ denotes the linear mass of the material transferred, and $\delta_{j}$ denotes the belt section inclination angle. Since the system is unloaded in the return side, the resistance factor due to the conveyed material $m_{L, j}^{\prime}$ will not apply to the belt sections situated in the lower stretch. The total mass $m_{R, j}$ of the rotating parts of a idler roll is approximated by:

$$
m_{R, j}=z_{1} D_{j}^{z_{2}} B^{z_{3}}+z_{4} d_{j},
$$

where $z_{1}$ to $z_{5}$ are the model coefficients, $D_{j}$ denotes the shell diameter of idler rolls in the belt section $j$, and $d_{j}$ denotes the shaft diameter of idler rolls in the same belt section.

The secondary resistance $F_{N, j}$ in a belt section $j$ entails the frictional resistances $F_{A u f, j}, F_{S c h b, j}$, and $F_{G r, j}$. These resistances are modeled as follows:

$$
\begin{gathered}
F_{A u f, j}=\frac{Q}{\rho}\left(v-v_{0, j}\right), \\
F_{S c h b, j}=C_{S c h b} C_{R a n k}\left[\frac{2 Q}{\left(v+v_{0, j}\right) \rho^{2}}-\left(b_{S c h}^{2}-l_{M, o}^{2}\right) \frac{\tan \lambda}{4}\right]^{2} \frac{\rho g l_{b} \mu_{2}}{b_{S c h}^{2}}, \\
F_{G r, j}=\mu_{3} p_{G r} A_{G r} .
\end{gathered}
$$

In equations (9) to (11), $v_{0, j}$ denotes the initial speed of the material in the direction of the belt travel, $C_{S c h b}$ denotes a constant factor for the additional resistance between material loaded and lateral chutes, $C_{\text {Rank }}$ denotes Rankine coefficient, $b_{S c h}$ denotes the clear width of lateral chutes, $l_{b}$ denotes the total length of the acceleration path, $\lambda$ denotes the troughing angle, $\mu_{2}$ denotes the friction factor between lateral chutes and material transferred, $\mu_{3}$ denotes the friction factor between belt cleaning device and belt, $p_{G r}$ denotes the pressure between belt cleaning device and belt, and $A_{G r}$ denotes the effective contact area between belt cleaning device and belt. $A_{G r}, b_{S c h}$ and $l_{b}$ are determined as follows

$$
\begin{gathered}
A_{G r}=w B, \\
b_{S c h}=a l_{M, o}, \\
l_{b}=\frac{k_{b}\left(v^{2}-v_{0, j}^{2}\right)}{2 g \mu_{1}},
\end{gathered}
$$

where $w$ denotes the width of the contact area between belt and belt cleaning device, $\mu_{1}$ denotes the friction factor between belt and material conveyed and $a$ and $k_{b}$ are constant coefficients.

In addition to the normal distribution of the secondary resistance components as in the single drive conveyor systems, the inertia resistance and the frictional resistance between lateral chutes and the belt given, respectively, by (9) and (10), also occur in each belt section situated in the downstream of an intermediate drive station.

The gradient resistance $F_{G, j}$ caused by the lifting of the belt and the material in a belt section $j$ is given by

$$
F_{G, j}=l_{j} \sin \delta_{j}\left(m_{G}^{\prime}+m_{L, j}^{\prime}\right) g,
$$

in which $\delta_{j}>1$ for uphill belt travel and $\delta_{j}<1$ for downhill belt travel.

The special resistance component $F_{S, j}$ concerns the remaining resistances that apply only to particular conveyor designs. It includes the camber resistance, the resistance due to any lateral transfer equipment positioned along the conveyor path and the frictional resistance between lateral chutes and transferred material beyond the loading zones.

The overall resistance to the belt movement in a belt section $j$ is therefore given by

$$
F_{W, x, j}=F_{H, x, j}+\underset{10}{F_{N, x, j}}+F_{G, x, j}+F_{S, x, j},
$$


where the subscript $x$ is replaced by $o$ for the upper stretch or by $u$ for the lower stretch. The overall resistance to the movement $F_{W}$ can be therefore expressed as follows:

$$
F_{W}=\sum_{j=1}^{N_{o}} F_{W, o, j}+\sum_{j=1}^{N_{u}} F_{W, u, j} .
$$

\subsection{Power balance of the belt conveyor}

The following condition ensures the power balance over the entire multi-drive conveyor system:

$$
2 \sum_{i=1}^{N+1} P_{i} \eta_{\text {gear }, i}-v F_{W}=0
$$

where $\eta_{\text {gear }, i}$ denotes the efficiency of the gear reducers in the $i$-th drive station.

The power balance within the driving subsystems of each drive station is guaranteed by verifying:

$$
\frac{2 T_{i} v}{D_{t r, i}}=\eta_{\text {gear }, i} P_{i}, \quad i=1, \ldots, N+1 .
$$

Going a step further from equation (13), the force balance at the drive stations can be determined. First, the minimum belt tension need to be determined. For $N_{u}=3$ and depending on the magnitude of the gradient resistances in the belt sections 1 and 3 in the lower stretch, the minimum belt tension $F_{\min }$ will normally occur either at the tail pulley or at the slack side the drive station situated in the return side. In case the take-up device is fitted at the point of minimum belt tension, the belt tension $F_{0}$ at the tail pulley is given by

$$
F_{0}=\left\{\begin{array}{l}
F_{T U}, \quad \text { if } F_{\text {min }}=F_{0}, \\
F_{T U}+F_{W, o, 1}+F_{W, o, 3}, \quad \text { if } F_{m i n}=F_{T 2, N+1} .
\end{array}\right.
$$

Following the direction of the belt movement, the tight side tension of a $i$-th drive station is calculated by subtracting the total driving force due to all the drive stations located between the tail pulley and this drive station from the sum of $F_{0}$ and the total resistance of all the belt sections situated between the tail pulley and the tight side of the drive station concerned. The tight side tension of each of the $N+1$ drive stations of a multi-drive conveyor is therefore obtained by

$$
F_{T 1, i}=\left\{\begin{array}{l}
F_{0}+F_{W, o, i}, \quad \text { if } i=1, \\
F_{0}+\sum_{k=1}^{2 i-1} F_{W, o, k}-2 \sum_{k=1}^{i-1} P_{k} \eta_{k} / v, \quad \text { if } 2 \leq i \leq N \\
F_{0}+\sum_{k=1}^{2 i-1} F_{W, o, k}+F_{W, u, N_{u}}-2 \sum_{k=1}^{i-1} P_{k} \eta_{k} / v, \quad \text { if } i=N+1 .
\end{array}\right.
$$

As shown in Fig. 1, the maximum belt tension under steady operating conditions is reduced in multidrive belt conveyors through the equalization of the tight side belt tensions of all the drive stations installed in the conveyor system $[32,34]$. Hence, the following condition must be satisfied:

$$
F_{T 1, i}=F_{T 1,1}, \quad i=2, \ldots, N+1 .
$$

Within a drive station, the slack side tension is equal to the difference between the tight side tension and the total tensile force transmitted by its gear reducers:

$$
F_{T 2, i}=F_{T 1, i}-2 P_{i} \eta_{\text {gear }, i} / v, \quad i=1, \ldots, N+1 .
$$

To guarantee the effective transmission of the driving forces from the drive pulleys to the belt, the slack side tension of each drive station should verify:

$$
F_{T 2, i}-2 C_{w, i} P_{i} \eta_{\text {gear }, i} / v \geq 0, \quad i=1, \ldots, N+1
$$


where the combined wrap factor $C_{w, i}$ of a $i$-th drive station can be obtained by [35]

$$
C_{w, i}=\frac{1}{e^{2 \mu \alpha_{i}}-1}, \quad i=1, \ldots, N+1,
$$

by assuming that the friction factor $\mu$ between drive pulley and conveyor belt is constant for the entire conveyor.

\subsection{Design constraints}

\subsubsection{Material transportation requirements}

The conveyor must transport a required flow rate of material over a specific distance. The following equation ensures the required material flow

$$
Q=\rho A_{t h} v
$$

where the theoretical cross section of fill $A_{t h}$ for a three-idler troughing configuration shown in Fig. 3(a) is given by

$$
A_{t h}=\left[l_{M, o}+\left(b-l_{M, o}\right) \cos \lambda\right]^{2} \frac{\tan \beta}{4}+\left(l_{M, o}+\frac{b-l_{M, o}}{2} \cos \lambda\right) \frac{b-l_{M, o}}{2} \sin \lambda .
$$

The following condition needs to be satisfied to ensure the desired the transportation distance $L$ of the material

$$
\sum_{k=1,3, \ldots}^{N_{o}} L_{o, k}-\sum_{i=1}^{N} D_{t r, i}=L / \cos \delta,
$$

\subsubsection{Safety and endurance requirements}

The design constrains relating to the operation safety and endurance of the conveyor are discussed here. To ensure operational safety, the following conditions apply to the belt tension at the tail pulley and the slack side tension of intermediate drive stations in order to limit the belt sag in the upper stretch below a specified value $h_{\text {rel }}[33]$ :

$$
\begin{gathered}
F_{0} \geq \frac{g\left(\rho A_{t h}+B \gamma_{\text {belt }}\right) l_{o}}{8 h_{\text {rel }}}, \\
F_{0}+\sum_{j=1}^{k} F_{W, o, j}-2 \sum_{r=1}^{m} \frac{\eta_{r} P_{r}}{v} \geq \frac{g\left(\rho A_{t h}+B \gamma_{b e l t}\right) l_{o}}{8 h_{\text {rel }}},
\end{gathered}
$$

for $k=2,4, \ldots, N_{o}-1, m=\left\lceil\frac{k-1}{2}\right\rceil$, and where $\gamma_{b e l t}$ denotes the specific mass of the belt. The function $\lceil\cdot\rceil$ is the ceiling function which rounds a real number upwards to the nearest integer. Similarly, the belt sag in the lower stretch is maintained below the same value by applying the following condition at the spot of the minimum belt tension:

$$
F_{T U} \geq \frac{g B \gamma_{b e l t} l_{u}}{8 h_{r e l}} .
$$

Belt manufacturers' product datasheets provide the following type of relation between $\gamma_{b e l t}$ and $k_{N}$

$$
\gamma_{b e l t}=m_{1}+m_{2} k_{N},
$$

where $m_{1}$ and $m_{2}$ are the model coefficients.

The nominal breaking strength of the belt related to belt width and the maximum belt tension, which coincides with the tight side tension of the drive stations, should satisfy

$$
\frac{k_{t, r e l} k_{N}}{S_{0} S_{1}} \geq \frac{F_{T 1,1}}{B} .
$$


where $k_{t, r e l}$ denotes the relative reference endurance strength of the belt, $S_{0}$ denotes the belt safety factor related to the splicing conditions, and $S_{1}$ denotes the belt safety factors related to the expected lifetime, the operational conditions and the dynamics of the conveyor.

The following condition ensures that the strength of the longitudinal tensile members in the belt core endures over the expected lifetime of the belt

$$
D_{t r, i} \geq c_{T r} d_{G k}, \quad i=1, \ldots, N+1,
$$

where $c_{T r}$ denotes a constant factor that depends on the type of the longitudinal tensile members and $d_{G k}$ denotes their thickness.

In case of steelcord belts, the manufacturers' product datasheets provide the following relation between $d_{G k}$ and $k_{N}$ :

$$
d_{G k}=m_{3}+m_{4} k_{N}^{m_{5}},
$$

where $m_{3}, m_{4}$ and $m_{5}$ are the model coefficients.

As per the SANS 1313 standard, the admissible load-carrying capacities $F_{\max , o}$ and $F_{\max , u}$ of, respectively, the carry and return idler rolls are specified in relation to the diameters of their shafts and the belt width [36]. To further prevent risks of premature failure, the idler rolls in the upper strecth are also subjected to the following condition [37]:

$$
S_{f} B_{f} L_{f} F_{s, o} \leq F_{\max , o},
$$

where $S_{f}, B_{f}$, and $L_{f}$ denote the dynamic load factors related to, respectively, the belt speed, the bearing life, and the lump size of the material transported. $F_{s, o}$ denotes the static load on the central idler roll, which is determined by

$$
F_{s, o}=\left\{\gamma_{b e l t} l_{M, o}+\frac{1}{2} \rho l_{M, o}\left[\frac{1}{2} l_{M, o} \tan \beta+\left(b-l_{M, o}\right)(\sin \lambda+\cos \lambda \tan \beta)\right]\right\} g l_{o} .
$$

The variation of $S_{f}$ with respect to $v$ is described by [37]:

$$
S_{f}=n_{1}+n_{2} v
$$

where $n_{1}$ and $n_{2}$ are the model coefficients.

Similarly, the following condition applies to idler rolls situated in the lower stretch

$$
S_{f} B_{f} C_{f} F_{s, u} \leq F_{\max , u},
$$

where $C_{f}$ denotes the belt flap factor and the static load $F_{s, u}$ on a flat return idler is given by

$$
F_{s, u}=\gamma_{b e l t} l_{M, u} g l_{u} .
$$

While complying again with the SANS 1313 standard, the rotation speed of each idler roll should not exceed the limit of $750 \mathrm{rpm}$ [36]. This composes a constraint on the following relationship between the conveyor speed $v$ and the idler roll diameters $D_{o}$ and $D_{u}$

$$
\begin{aligned}
& \frac{60 v}{\pi D_{o}} \leq 750, \\
& \frac{60 v}{\pi D_{u}} \leq 750 .
\end{aligned}
$$




\subsubsection{Standardization requirements}

In case the use of identical equipment and settings is required for supply chain and operational motivations, the following constraints will apply along with the previous design conditions:

$$
\begin{aligned}
P_{i} & =P_{1}, \\
T_{i} & =T_{1}, \\
D_{t r, i} & =D_{t r, 1}, \\
\alpha_{i} & =\alpha_{1},
\end{aligned}
$$

for $i=2, \cdots, N+1$.

\subsubsection{Boundary limits}

Lastly, the design parameters are subject to the following boundary limits:

$$
\begin{gathered}
0 \leq P_{i} \leq P_{\text {max }} \\
0 \leq T_{i} \leq T_{\text {max }} \\
D_{t r, i} \in \mathfrak{D}_{t r} \\
\alpha_{\text {min }} \leq \alpha_{i} \leq \alpha_{\text {max }} \\
L_{\text {min }} \leq L_{o, j} \leq L_{\text {max }} \\
B \in \mathfrak{B} \\
0 \leq v \leq v_{\text {max }} \\
0 \leq k_{N} \leq k_{N, \text { max }} \\
0 \leq F_{T U} \leq F_{T U, \max } \\
l_{o, \min } \leq l_{o} \leq l_{o, \max } \\
l_{u, \min } \leq l_{u} \leq l_{u, \max } \\
D_{o} \in \mathfrak{D} \\
D_{u} \in \mathfrak{D} \\
d_{o} \in \mathfrak{d} \\
d_{u} \in \mathfrak{d}
\end{gathered}
$$

In the above equations, the subscripts min and max denote, respectively, the lower and upper limits of the related design parameters, $\mathfrak{D}_{t r}$ denotes the set of recommended diameters of the drive pulleys, $\mathfrak{B}$ denotes the set of recommended belt width, $\mathfrak{D}$ denotes the set of recommended diameters of the idler rolls and $\mathfrak{d}$ denotes the set of recommended shaft diameters of the idler rolls.

Based on the above development, the optimization problem that minimizes the life cycle cost of the multi-drive belt conveyors fitted with $N$ intermediate drive stations is

$$
\begin{array}{cl}
\min _{X} & \text { Eq. }(7) \\
\text { s.t. } & \text { Eqs. }(13)-(46),
\end{array}
$$

For readability reasons, the full optimization program is reproduced in Appendix B.

\section{Case Study}

A simulation based case study is presented in this section to demonstrate the effectiveness of the optimal multi-drive belt conveyor design model proposed. 


\subsection{Simulation setup}

The requirement is to design a multi-drive belt conveyor capable of transporting a certain bulk material with a flow rate of $3500 \mathrm{t} / \mathrm{h}$ over a distance of $2500 \mathrm{~m}$ with an inclination of 1 in 100 . The description of this transportation task along with the technical parameters are listed in Table 1 . In practice, the value of the hypothetical friction factor is affected by several factors, including the belt tension, conveyor speed, diameters of idler rolls and their spacing as explained in the DIN 22101 standard [33]. While it usually varies between 0.010 and 0.040 , no approach to set $f$ is mentioned in case its affecting parameters are independently varied between their usual limits. Accordingly, a fixed value of 0.03 is adopted in this study as mentioned in Table 1. For a certain design task, this should be picked by the plant designer who has knowledge about this factor. Further, the case study assumes a unique loading point at the tail pulley, a unique unloading point at the head pulley and a single belt cleaning device installed downstream of the head pulley. The standard values of $F_{\max , o}$ and $F_{\max , u}$ applicable to, respectively, three-idler troughing configurations and flat return idler rolls for common belt widths and shaft diameters as considered in this case study are disclosed in [36].

The cost implications of the optimally designed multi-drive conveyor is compared with that of an optimally designed single drive conveyor for a fair comparison. In particular, an optimization model for the design of single drive belt conveyors with a unique head drive pulley was developed. This model is a modification of the design model for multiple drive belt conveyors presented earlier in this study with the number of intermediate drive stations $N$ set to zero. Certain design conditions among (17)-(14) and (15)-(27) were also modified to reflect the absence of intermediate stations and the use of a unique drive pulley in the belt conveyor.

Table 1: Technical parameters of the case study

\begin{tabular}{|c|c|c|c|c|c|}
\hline Parameter & Value & Unit & Parameter & Value & Unit \\
\hline Transport parameters & & & $m_{2}$ & $8.174 \cdot 10^{-3}$ & \\
\hline$L$ & 2500 & $\mathrm{~m}$ & $m_{3}$ & 1.002 & \\
\hline$H$ & 25 & $\mathrm{~m}$ & $m_{4}$ & 0.0124 & \\
\hline$Q$ & 3500 & $\mathrm{t} / \mathrm{h}$ & $m_{5}$ & 0.771 & \\
\hline$\rho$ & 1280 & $\mathrm{~kg} / \mathrm{m}^{3}$ & $S_{0}$ & 1.1 & \\
\hline$\beta$ & 20 & $\circ$ & $S_{1}$ & 1.7 & \\
\hline$L_{f}$ & 1 & & Drive station parameters & & \\
\hline$h_{r e l}$ & 1 & $\%$ & $\mu$ & 0.3 & \\
\hline Resistance parameters & & & $\eta_{\text {gear }}$ & 0.9 & \\
\hline$a$ & 1.25 & & $\eta_{m o t}$ & 0.95 & \\
\hline$C_{S c h b} C_{R a n k}$ & 1 & & Idler roll parameters & & \\
\hline$f$ & 0.03 & & $n_{1}$ & 0.714 & \\
\hline$g$ & 9.81 & $\mathrm{~m} / \mathrm{s}^{2}$ & $n_{2}$ & 0.089 & \\
\hline$k_{b}$ & 1.1 & & $B_{f}$ & 0.80 & \\
\hline$v_{0, j}$ & 0 & $\mathrm{~m} / \mathrm{s}$ & $C_{f}$ & 1.25 & \\
\hline$\mu_{1}$ & 0.6 & & Carry idler roll parameters & & \\
\hline$\mu_{2}$ & 0.6 & & $z_{1, o}$ & 139.39 & \\
\hline$\mu_{3}$ & 0.65 & & $z_{2, o}$ & 1.722 & \\
\hline$p_{G r}$ & 0.065 & $\mathrm{~N} / \mathrm{mm}^{2}$ & $z_{3, o}$ & 1.025 & \\
\hline & 0.031 & $\mathrm{~mm}$ & $z_{4, o}$ & 80.51 & $\mathrm{~kg} / \mathrm{m}$ \\
\hline Belt parameters & & & Return idler roll parameters & & \\
\hline$\lambda$ & 35 & $\circ$ & $z_{1, u}$ & 172 & \\
\hline$c_{T r}$ & 145 & & $z_{2, u}$ & 1.287 & \\
\hline$k_{t, r e l}$ & 0.45 & & $z_{3, u}$ & 1 & \\
\hline$m_{1}$ & 13.823 & & $z_{4, u}$ & 124.99 & $\mathrm{~kg} / \mathrm{m}$ \\
\hline
\end{tabular}




\subsection{Economic parameters and assumptions}

Table 2 displays the economic parameters and assumptions considered in the simulation study. The straight line depreciation method is adopted for all the conveyor components and the depreciation costs remaining at the end of the project lifetime are written off. Further the annual cost escalation rate of the different equipment is assumed equal to the inflation rate given in Table 1. While the lifetimes of the belts, motors and gearbox follow the recommendations of the US Bureau of Economic Analysis (BEA) [38], that of the idler rolls is fixed at 40000 hours in accordance with SANS 1313 standard [36]. The salvage values are however assumed by the authors. Using the calculation method described in Appendix A, the following equivalent annual cost coefficients were obtained: $k_{1}=1.653, k_{2}=0.138, k_{3}=0.055, k_{4}=0.055$, $k_{5}=0.148, k_{6}=0.148$.

With regard to the equipment prices, the initial cost coefficients indicated in Table 2 were determined from information provided by suppliers in South Africa or abroad, with an estimate of the shipping costs for the latter case. The interested reader is referred to reference [39] for calculation details. Note that while the relative differences between the energy and component costs may vary by country, this study aims to provide the basic principles by which economic design of multiple drive belt conveyors may be achieved.

Table 2: Economic parameters of the case study

\begin{tabular}{|c|c|}
\hline Description & Value \& Unit \\
\hline \multicolumn{2}{|l|}{ General parameters } \\
\hline project lifetime, $Z$ & 20 years \\
\hline running time, $t_{a}$ & 12 hours/day over 300 days par annum \\
\hline initial energy cost, $e_{o}$ & $0.071 \mathrm{USD} / \mathrm{kWh}$ \\
\hline annual escalation rate of energy costs, $r_{e}$ & $11.19 \%$ \\
\hline inflation rate & $5.6 \%$ \\
\hline tax rate & $28 \%$ \\
\hline proportion of debt capital & $0 \%$ \\
\hline $\begin{array}{l}\text { after tax return required on equity funds with } \\
0 \% \text { inflation rate }\end{array}$ & $5 \%$ \\
\hline \multicolumn{2}{|l|}{ Belt parameters } \\
\hline expected lifetime & 16 years \\
\hline salvage value & \\
\hline initial cost coefficients, $c_{1} ; c_{2} ; c_{3}$ & $25.965 ; 0.0014 ; 1.313$ \\
\hline belt length coefficients, $y_{1} ; y_{2}$ & $3 \mathrm{~m} ; 20 \mathrm{~m}$ \\
\hline \multicolumn{2}{|l|}{ Motors } \\
\hline expected lifetime & 16 years \\
\hline salvage value & \\
\hline initial cost coefficients, $c_{4} ; c_{5} ; c_{6}$ & $248.12 ; 69.062 ; 1.013$ \\
\hline \multicolumn{2}{|l|}{ Gear reducers } \\
\hline expected lifetime & 16 years \\
\hline salvage value & $10 \%$ \\
\hline initial cost coefficients, $c_{7} ; c_{8} ; c_{9}$ & $5699.3 ; 1563.1 ; 1.081$ \\
\hline \multicolumn{2}{|l|}{ Carry idler rolls } \\
\hline expected lifetime & 11 years \\
\hline salvage value & \\
\hline $\begin{array}{l}\text { initial cost coefficients, } c_{10} ; c_{11} ; c_{12} ; c_{13} ; c_{14} \\
c_{15} ; c_{16}\end{array}$ & $-69.77 ; 1.312 \cdot 10^{-5} ; 3.096 ; 4.828 ; 1 ; 1.079 \cdot 10^{-4} ; 1.829$ \\
\hline \multicolumn{2}{|l|}{ Return idler rolls } \\
\hline expected lifetime & 11 years \\
\hline salvage value & \\
\hline $\begin{array}{l}\text { initial cost coefficients, } c_{17} ; c_{18} ; c_{19} ; c_{20} ; c_{21} \\
c_{22} ; c_{23}\end{array}$ & $-30.5 ; 0.565 ; 0.676 ; 0.571 ; 1.054 ; 0.567 ; 0.676$ \\
\hline
\end{tabular}


The lower limits, upper limits, and set of possible values that apply to the various design parameters are summarized in Table 3.

Table 3: Boundary limit values

\begin{tabular}{|lcccl|}
\hline Parameter & Unit & Min & Max & Set \\
\hline$P_{i}$ & $\mathrm{~kW}$ & 0 & 2000 & - \\
$T_{i}$ & $\mathrm{kNm}$ & 0 & 950 & - \\
$D_{t r, i}$ & $\mathrm{~m}$ & - & - & $0.1-0.16-0.2-0.25-0.315-0.4-0.5-0.63-0.8-1-1.25-1.4-1.6-1.8-2-2.2$ \\
$\alpha_{i}$ & $\circ$ & 180 & 240 & - \\
$L_{o, j}$ & $\mathrm{~m}$ & 0 & 2500 & - \\
$B$ & $\mathrm{~m}$ & - & - & $0.6-0.75-0.9-1.05-1.2-1.35-1.5-1.8-2-2.2-2.4$ \\
$v$ & $\mathrm{~m} / \mathrm{s}$ & 0 & 10 & - \\
$k_{N}$ & $\mathrm{kN} / \mathrm{m}$ & 0 & 3000 & - \\
$F_{T U}$ & $\mathrm{kN}$ & 0 & 500 & - \\
$l_{o}$ & $\mathrm{~m}$ & 1 & 2 & - \\
$l_{u}$ & $\mathrm{~m}$ & 1 & 4.5 & - \\
$D_{o}, D_{u}$ & $\mathrm{~mm}$ & - & - & $63-76-89-102-108-127-133-152-159-194$ \\
$d_{o}, d_{u}$ & $\mathrm{~mm}$ & - & - & $25-30-35-40$ \\
\hline
\end{tabular}

\subsection{Results and discussions}

The above optimization problems of the economic design of single and multi-drive conveyors are formulated as mixed integer non-linear programming (MINLP) problems and were solved using the MIDACO solver, which is a general-purpose solver based on an extended evolutionary ant colony optimization algorithm [40]. For a given $N$, an MINLP problem is generated and subsequently solved by the optimizer in order to determine the most cost-effective conveyor design for the considered number of intermediate drive stations. Then, a different $N$ is set and the resulting MINLP problem is solved again. At the end, all solutions are compared to each other to determine the best design in terms of $N$ and other parameters.

Following Subsection 4.3.4, the design parameters $D_{t r, i}, B, D_{o}, D_{u}, d_{o}$ and $d_{u}$ were specified as discrete variables in the solver because of the limited number of recommended sizes [33,36]. Treated as of integer type during the internal optimization process, the values of these parameters in each of the solutions generated are first mapped to the corresponding actual sizes of the sets prescribed in Table 3 prior to evaluating the objective and constraint functions.

For illustration purposes, Fig. 4 displays the equivalent annual cost of conveyors obtained for all the possible widths of belt and a number of intermediate drive stations limited at 5 . The conveyor designs with zero intermediate drive station corresponds to the single drive belt technology. This figure shows that, in general, the economic benefits of the multi-drive technology will be more effective at low conveyor speed, while the single drive design will be the most beneficial option at high conveyor speed. A larger impact of the conveyor speed is also noted on the multiple drive conveyors compared to the single drive belt conveyors.

The synthesis of the lowest equivalent annual cost with respect to number of intermediate drive stations fitted is shown in Fig. 5 along with their respective energy and capital costs. This figure shows that the belt conveyor fitted with three intermediate drive stations operating at $1.69 \mathrm{~m} / \mathrm{s}$ constitutes the most costeffective design for the considered transport operation. By adopting the most economic single-drive belt conveyor as the reference conveyor, the equivalent annual cost savings expected from the most cost-effective multi-drive conveyor is estimated at approximately $63131 \$(\mathrm{USD})$ per annum over the 20 years of the project lifetime.

Regarding operating and capital costs, Fig. 5 shows that the observed decrease in cost in comparison with the reference conveyor is primarily due to the lower energy expenses involved. Especially, within the $63131 \$$ (USD) of cost savings achieved, $62.44 \%$ savings come from energy costs and the other $35.56 \%$ from the capital costs. With the increase in the number of drive stations, the energy cost tends to decline, while a decrease in the capital cost is first observed, followed by a progressive increase. The variation in the energy cost is, however, slowed by the extra inertia resistance and frictional resistance brought in by every 


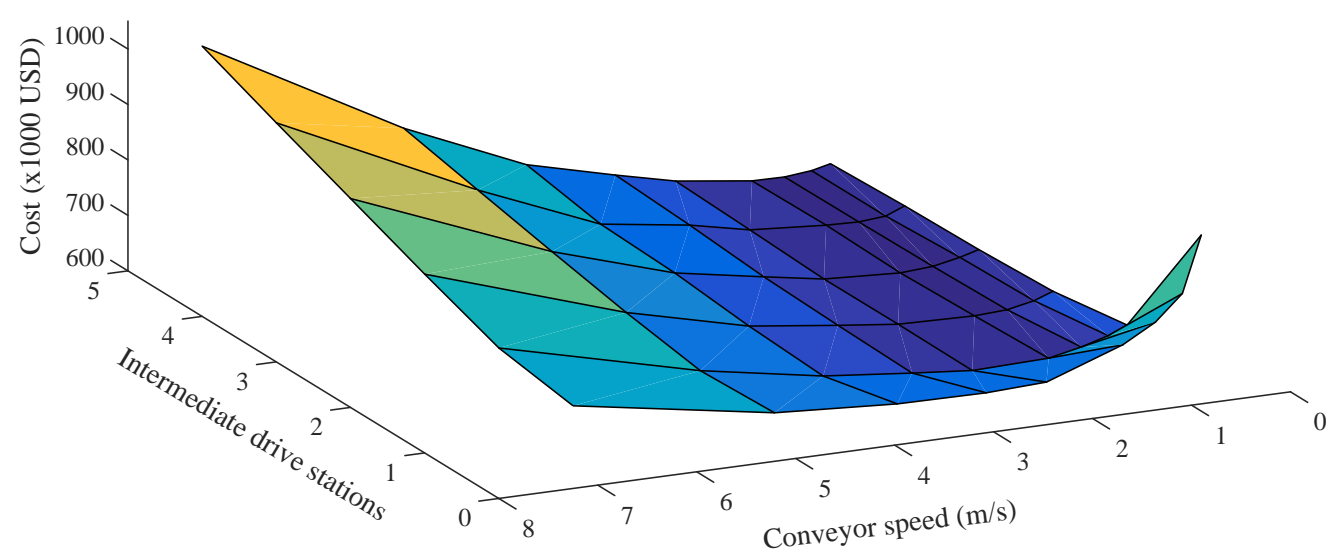

Figure 4: Optimal belt conveyor cost vs Belt speed vs Intermediate drives

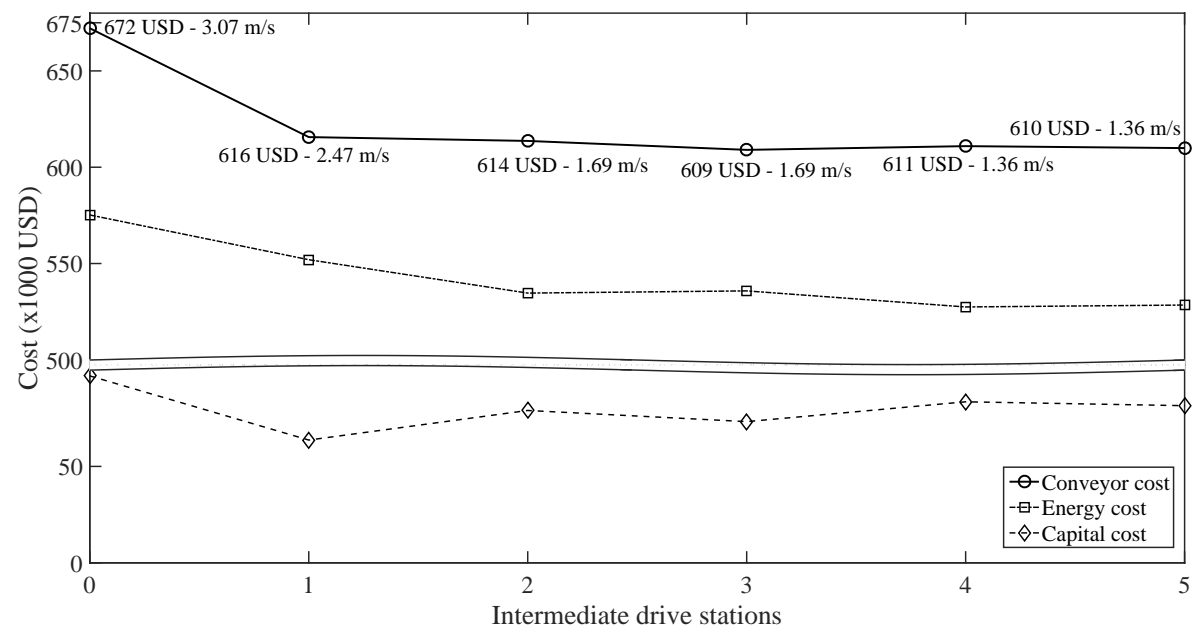

Figure 5: Minimum belt conveyor cost per number of intermediate stations

additional drive station fitted in the conveyor system. Fig. 5 also indicates that the optimal conveyor speed decreases gradually as more drive stations are fitted.

The breakdown of the power consumption per load component shown in Fig. 6 suggests that every additional drive station can assist to achieve higher energy efficiency in transportation, because of the reduction in energy consumption from the belt and the idler rolls. Accordingly, and given (8) and (12), higher cost savings can therefore be expected for conveyors with longer transport distances.

To investigate the individual contributions of the conveyor components in the capital costs, Fig. 7 is presented. It is observed that the cost of the belt will generally form the largest portion, followed by the gear reducers. Beyond a single intermediate drive station, the cost savings induced by the use of lighter belts are balanced and gradually defeated by the need for larger belts. For the motors, Fig. 7 indicates that their cost is fairly stable, irrespective of the number of drive stations. Lastly, the belt width has a greater impact on the cost of carry idler rolls than that of the return idler rolls.

In order to evaluate the validity of the previous simulation results in case of the inflation rate fluctuation throughout the project lifetime, two additional scenarios were simulated. The first scenario considers net decrease of $5 \%$ in the initial inflation rate accompanied by a stochastic factor restrained at $\pm 0.1 \%$. An average inflation rate of $5.2 \%$ with a minimum of $4.8 \%$ and a maximum $5.8 \%$ was observed in this case, which resulted in the following equivalent annual cost coefficients: $k_{1}=1.716, k_{2}=0.138, k_{3}=0.053, k_{4}=0.052$, $k_{5}=0.145, k_{6}=0.145$. The second scenario consisted of a net increase of $5 \%$ in the initial inflation rate, accompanied by another stochastic factor also restrained at $\pm 0.1 \%$. An average inflation rate of $5.8 \%$ with a minimum of $5.4 \%$ and a maximum $6.4 \%$ was observed in this case, which resulted in the following equivalent annual cost coefficients: $k_{1}=1.613, k_{2}=0.137, k_{3}=0.057, k_{4}=0.057, k_{5}=0.147, k_{6}=0.147$. 


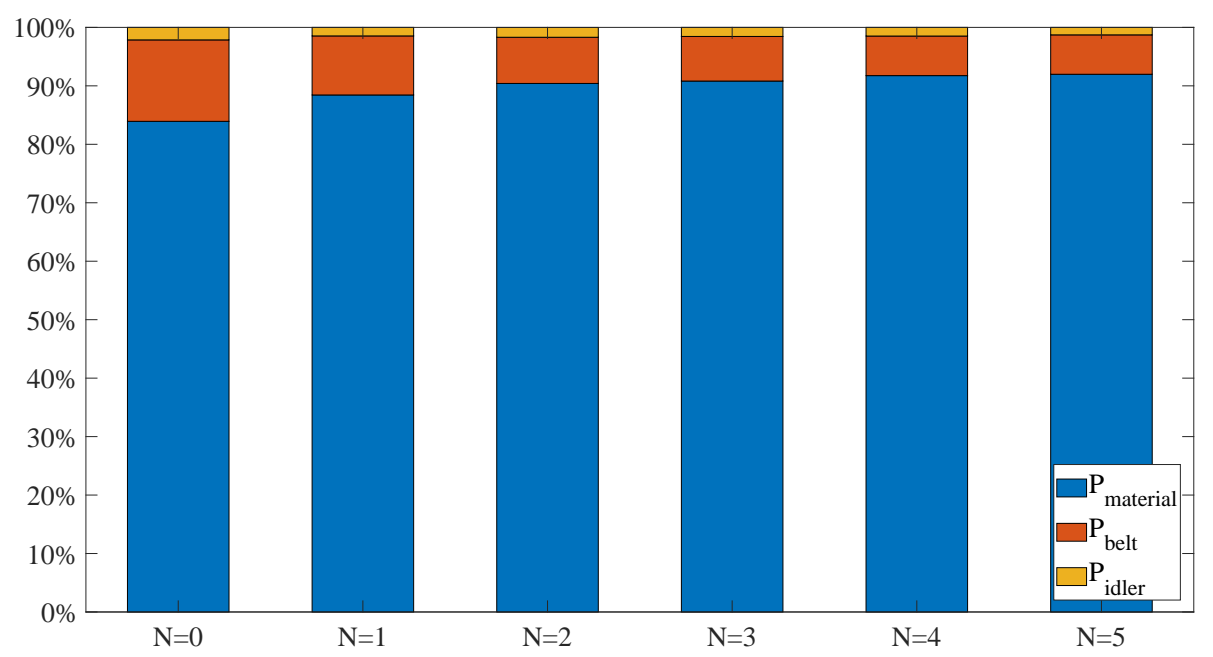

Figure 6: Power consumption per conveyor load component

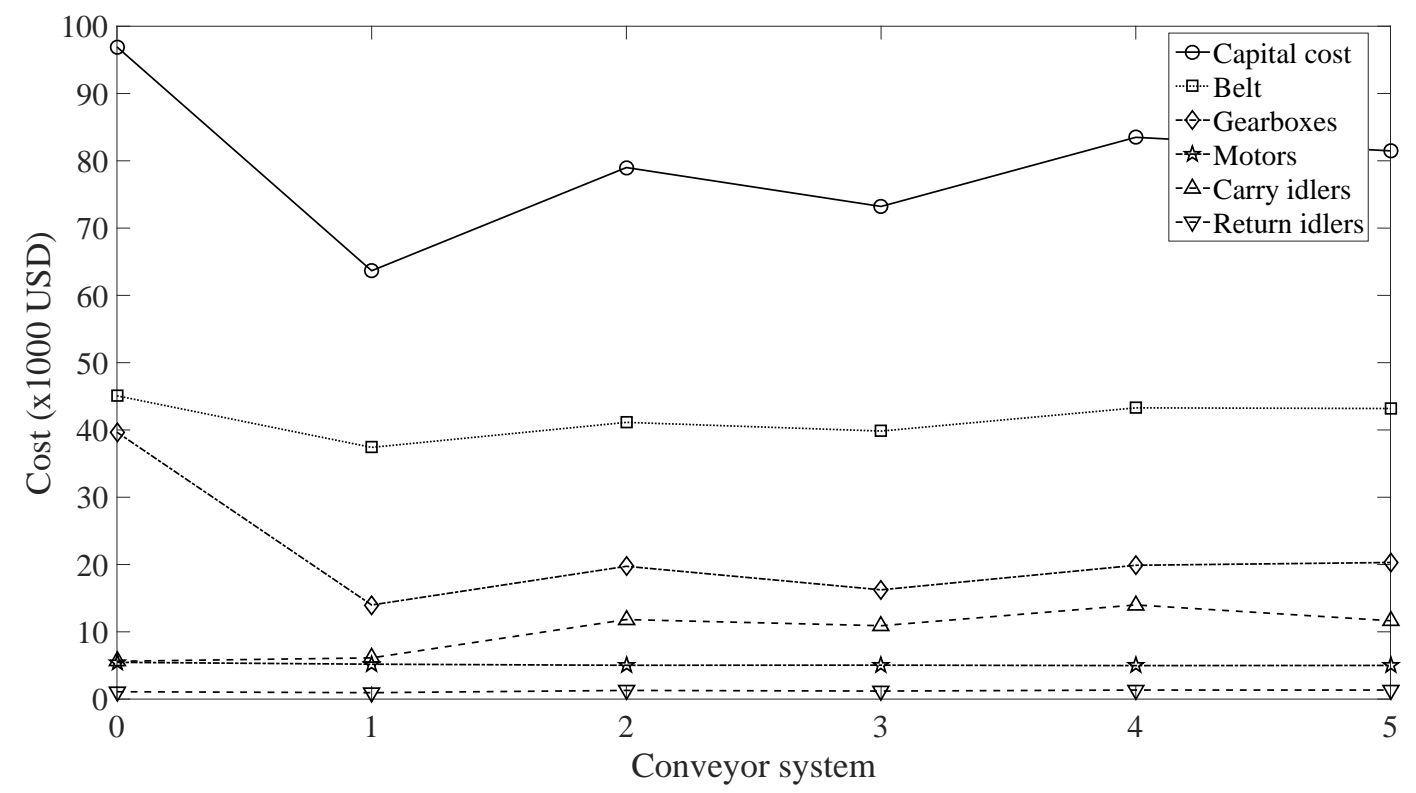

Figure 7: Detailed capital cost per belt conveyor component

Fig. 8 shows a synthesis of the most economic results with respect to the number of intermediate drive stations fitted in the conveyor system. The optimal design solution that involves 3 intermediate drive stations with a belt speed at $1.694 \mathrm{~m} / \mathrm{s}$ appears to remain the most advantageous option under the three scenarios. Detailed performance of the optimal design under each scenario are given in Table 4. The comparison of the three cost-effective design solutions shows that, apart from $\alpha_{i}, k_{N}, F_{T U}, l_{o}$ and $l_{u}$, the rest of design parameters maintain the same values under the three different scenarios. Further tests focusing on $\alpha_{i}$ showed that greater values can also apply to the original most cost-effective multi-drive belt conveyor, that is under $5.6 \%$ inflation rate, and the cheapest conveyor system under $5.2 \%$ inflation rate without affecting their respective economic performance. Such an increase on $\alpha_{i}$ will benefit the design condition (16) on the slack side tension of drive stations. Further the comparison of $k_{N}$ under the $5.2 \%$ and $5.8 \%$ inflation rate fluctuation scenarios with the fixed inflation scenario at $5.6 \%$ per year indicates a decrease of, respectively, $7.81 \%$ and $8.76 \%$ in this parameter in case the presumed fluctuations of inflation rate occur in course of the project. Also in comparison with the original most cost-effective multi-drive belt conveyor, it is observed a decrease of $l_{o}$ by $19.01 \%$ and $21.13 \%$ and an increase of $l_{u}$ by $15.38 \%$ and $15.38 \%$ under the $5.2 \%$ and $5.8 \%$ inflation rate fluctuation scenarios, respectively. This suggests that the additional expenses induced by the use of the original belt (greater $k_{N}$ ) and the original return idler roll spacing (smaller $l_{u}$ ) under the 


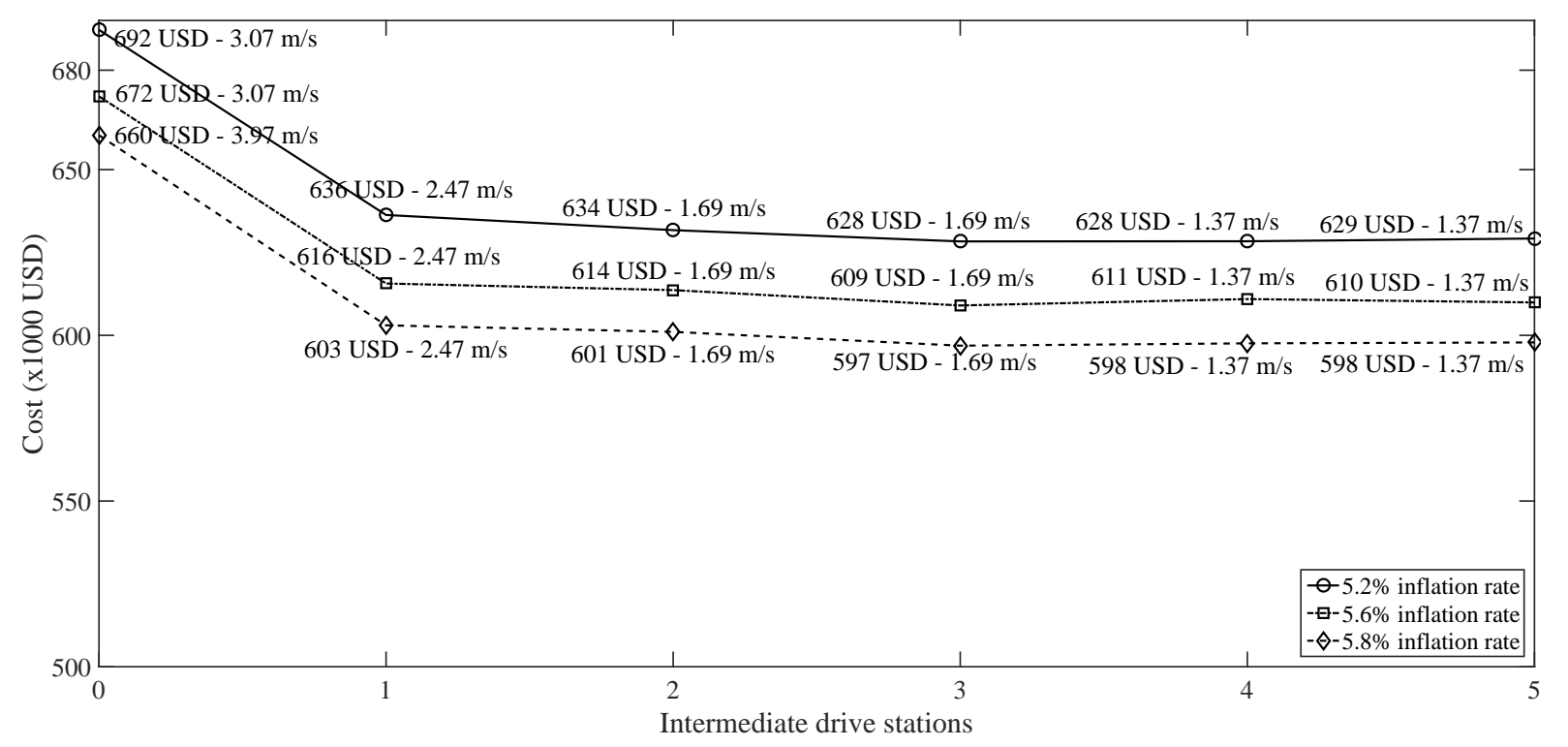

Figure 8: Variation of the cost-effective belt conveyors with the inflation rates

fluctuating inflation scenarios will be partially offset by gains resulting from the reduction in the quantity of carry idler rolls installed (greater $l_{o}$ ). In view of the preceding analysis, the original most cost-effective multi-drive belt conveyor is fairly robust in case of limited fluctuations of the inflation rate.

Table 4: Cost-effective belt conveyor designs under different inflation trends

\begin{tabular}{|l|c|c|c|}
\hline \multirow{2}{*}{ Parameter } & \multicolumn{3}{|c|}{ Average inflation rate } \\
\cline { 2 - 4 } & $5.2 \%$ & $5.6 \%$ & $5.8 \%$ \\
\hline$N$ & 3 & 3 & 3 \\
$P_{i}, \mathrm{~kW}$ & 151.05 & 151.09 & 151.08 \\
$v, \mathrm{~m} / \mathrm{s}$ & 1.69 & 1.69 & 1.69 \\
$T_{i}, \mathrm{kNm}$ & 16.05 & 16.05 & 16.05 \\
$L_{o, 1}, \mathrm{~m}$ & 574.63 & 572.98 & 574.77 \\
$L_{o, 3}, \mathrm{~m}$ & 649.14 & 649.7 & 649.1 \\
$L_{o, 5}, \mathrm{~m}$ & 649.14 & 649.7 & 649.1 \\
$L_{o, 7}, \mathrm{~m}$ & 628.41 & 628.94 & 628.35 \\
$\alpha_{i}, \mathrm{rad}$ & 3.32 & 3.8 & 4.19 \\
$l_{o}, \mathrm{~m}$ & 1.15 & 1.42 & 1.12 \\
$l_{u}, \mathrm{~m}$ & 4.5 & 3.9 & 4.5 \\
$F_{\text {TU }}, \mathrm{kN}$ & 67.67 & 86.95 & 65.26 \\
$k_{N}, \mathrm{kN} / \mathrm{m}$ & 526.68 & 571.28 & 521.22 \\
$B, \mathrm{~mm}$ & 1800 & 1800 & 1800 \\
$D_{o}, \mathrm{~mm}$ & 63 & 63 & 63 \\
$D_{u}, \mathrm{~mm}$ & 63 & 63 & 63 \\
$d_{o}, \mathrm{~mm}$ & 30 & 25 & 30 \\
$d_{u}, \mathrm{~mm}$ & 30 & 25 & 30 \\
$D_{\text {tr, }, \mathrm{mm}}, \mathrm{mm}$ & 400 & 400 & 400 \\
$A_{\text {energy }}, \times 1000 \mathrm{USD} /$ year & 556.16 & 535.79 & 522.84 \\
$A_{\text {belt }}, \times 1000$ USD/year & 39.02 & 39.83 & 38.66 \\
$A_{\text {motor }}, \times 1000$ USD/year & 4.82 & 5.04 & 5.22 \\
$A_{\text {gear }}, \times 1000$ USD/year & 15.51 & 16.24 & 16.82 \\
$A_{\text {carryidler }}, \times 1000$ USD/year & 11.56 & 10.9 & 12.05 \\
$A_{\text {returnidler }}, \times 1000$ USD/year & 1.27 & 1.19 & 1.28 \\
\hline
\end{tabular}


Table 4: Cost-effective belt conveyor designs under different inflation trends (continued)

\begin{tabular}{|l|c|c|c|}
\hline \multirow{2}{*}{ Parameter } & \multicolumn{3}{|c|}{ Average inflation rate } \\
\cline { 2 - 4 } & $5.2 \%$ & $5.6 \%$ & $5.8 \%$ \\
\hline$A_{\text {conveyor }}, \times 1000$ USD/year & 628.34 & 609.01 & 596.88 \\
\hline
\end{tabular}

Table 5 summarizes the operational environmental footprint of the cost-effective conveyors in the event they are supplied by a coal-fired power plant [1]. It shows that the design solution with four intermediate stations will ensure the lowest emission of $\mathrm{CO}_{2}$ and particulates and water consumption due to electricity generation, followed by the multi-drive conveyors fitted with five and three intermediates stations. In case priority is given to the economic aspects, the implementation of the most cost-effective system fitted with three intermediate station will result in a yearly reduction of $333.56 \mathrm{~kg}$ in $\mathrm{CO}_{2}$ emissions, 101.07 ton in particulate emissions and $471.69 \mathrm{kl}$ in water consumption due to electricity generation, with respect to the single drive contender. This shows that the multi-drive technology can help reduce the environmental nuisance of belt conveyors.

Table 5: Environmental assessment of cost-effective belt conveyors

\begin{tabular}{|c|c|c|c|c|}
\hline Design & $\begin{array}{c}\text { Energy } \\
(\mathrm{MWh} / \mathrm{yr})\end{array}$ & $\begin{array}{c}\mathrm{CO}_{2} \text { emiss. } \\
(\mathrm{kg} / \mathrm{yr})\end{array}$ & $\begin{array}{c}\text { Partic. emiss. } \\
\text { (ton/yr) }\end{array}$ & $\begin{array}{c}\text { Water use } \\
(\mathrm{kl} / \mathrm{yr})\end{array}$ \\
\hline $\mathrm{N}=0$ & 4917.31 & 4868.14 & 1475.19 & 6884.23 \\
$\mathrm{~N}=1$ & 4718.73 & 4671.54 & 1415.62 & 6606.22 \\
$\mathrm{~N}=2$ & 4570.60 & 4524.89 & 1371.18 & 6398.84 \\
$\mathrm{~N}=3$ & 4580.38 & 4534.58 & 1374.12 & 6412.54 \\
$\mathrm{~N}=4$ & 4466.51 & 4421.85 & 1339.95 & 6253.11 \\
$\mathrm{~N}=5$ & 4517.56 & 4472.38 & 1355.27 & 6324.58 \\
\hline
\end{tabular}

\section{Conclusion}

An original contribution to the cost-effective design of multiple drive belt conveyors was presented in this paper. To achieve the lowest life cycle cost for a specified material handling operation, the proposed design approach takes into account a significant number of parameters, including the number of intermediate drive stations, their distribution along the conveyor path and the conveyor speed. Simulations carried out on a practical transport operation established the validity and effectiveness of the proposed design approach. An expected annual cost saving of 63131 (USD) was achieved by the most cost-effective multi-drive conveyor over the best single drive alternative. This was accompanied by a yearly reduction of $333.56 \mathrm{~kg}$ in $\mathrm{CO}_{2}$ emissions, 101.07 ton in particulate emissions and $471.69 \mathrm{kl}$ in water consumption due to electricity generation. The robustness of the most cost-effective conveyor designs against the fluctuation of the inflation rate was also confirmed. It is concluded that multi-drive belt conveyors are more advantageous for long distance slow speed material transportation while single drive technology is preferable for short distance fast speed applications. The scope of future works includes adding the capital costs of other conveyor components such as the supporting structure, the pulleys and the take-up device, and also the substitution of the simplified frictional resistance models from the DIN 22101 standard by advanced belt movement models.

\section{Appendix A. Calculation of the equivalent annual cost coefficients of energy and equipment}

\section{Appendix A.1. Equivalent annual energy cost coefficient}

This section presents the approach on the determination of the equivalent annual energy cost coefficient in case the annual escalation rate of energy $r_{e}$ and the general inflation rate $r$ can vary from year to year. It therefore extends and also summarizes the procedure expalined in the literature [30,41]. In this context, $k_{1}$ is given by: 


$$
k_{1}=\left(\frac{a}{p}\right)_{Z}^{i_{f}^{0}} \sum_{i=1}^{Z}\left(\frac{p}{f}\right)_{i}^{i_{f}} \prod_{j=1}^{i}\left(1+r_{e, j}\right)
$$

where $\left(\frac{a}{p}\right)_{Z}^{i_{f}^{0}}$ denotes the capital recovery factor of the project, $\left(\frac{p}{f}\right)_{i}^{i_{f}}$ denotes the present equivalent cost factor over $i$-year period of time, $r_{e, j}$ denotes the annual escalation rate of energy during the year $j$ of the project, and $Z$ denotes the project lifetime. The capital recovery factor is obtained by:

$$
\left(\frac{a}{p}\right)_{Z}^{i_{f}^{0}}=\frac{i_{f}^{0}\left(1+i_{f}^{0}\right)^{Z}}{\left(1+i_{f}^{0}\right)^{Z}-1},
$$

where $i_{f}^{0}$, the time value of money when all cash flows are converted from inflated value to constant year zero value, is given by:

$$
i_{f}^{0}=\frac{(1-t) r_{d} i_{d}-r_{d} r_{a v g}}{1+r_{a v g}}+\left(1-r_{d}\right) i_{e} .
$$

Here, $t$ denotes the income tax rate, $r_{d}$ denotes the proportion of debt capital maintained constant by the company, $i_{d}$ denotes the interest rate on debt, $r_{\text {avg }}$ denotes the average general inflation rate over the project duration, and $i_{e}$ denotes the after-tax return required on equity funds with zero inflation rate. In case the general inflation rate can vary throughout the project, the present equivalent cost factor over $i$-year period of time is given by:

$$
\left(\frac{p}{f}\right)_{i}^{i_{f}}=\frac{1}{\prod_{j=1}^{i}\left(1+i_{f, j}\right)},
$$

where $i_{f, j}$ denotes inflation modified rate of return of the year $j$ of the project, which is expressed by:

$$
i_{f, j}=(1-t) r_{d} i_{d}+\left(1-r_{d}\right)\left[\left(1+r_{j}\right)\left(1+i_{e}\right)-1\right] .
$$

Here, $r_{j}$ denotes the general inflation rate during the year $j$ of the project.

The substitution of (A.2) and (A.4) into (A.1), taking into account (A.3) and (A.5), allows to determine the equivalent annual energy cost coefficient.

\section{Appendix A.2. Equivalent annual cost of equipment}

Considering an equipment (e.g. belt), one or several items can be required during the project as a function of the project duration and the expected lifetime of the equipment as well. In the rest of this section, the concept "equipment" will therefore refer to the set of items purchased throughout the project. Let $k_{e q}$ and $C_{e q, 0}$ denote, respectively, the equivalent annual cost coefficient of an equipment and the first costs of the first item purchased at the year zero of the project. The equivalent annual cost $A_{e q}$ of this equipment can be expressed as [30]:

$$
A_{e q}=k_{e q} C_{e q, 0} .
$$

It can be also obtained by multiplying the present equivalent of the capital costs $P E C_{e q}$ of the equipment by the capital recovery factor of the project:

$$
A_{e q}=\left(\frac{a}{p}\right)_{Z}^{i_{f}^{0}} P E C_{e q} .
$$

Taking into account the first item and the replacement items purchased during the project period, the present equivalent of the capital costs of an equipment is expressed by [30]: 


$$
P E C_{e q}=\frac{P E F_{e q}-P E V_{e q}-t P E D_{e q}}{1-t},
$$

where $P E F_{e q}$ denotes the present equivalent of the first costs of all the items, $P E V_{e q}$ denotes the present equivalent of the salvage values of all the items, and $P E D_{e q}$ denotes the present equivalent of depreciations of all the items.

Denote $M$ the expected lifetime of a given equipment, the total number of items to be purchased over the $Z$ years of the project, denoted by $R$ is given by:

$$
R=\left\lceil\frac{Z}{M}\right\rceil,
$$

The year $X_{i}$ of the purchase of the $i$-th item $(i=1, \ldots, R)$ is given therefore by:

$$
X_{i}=(i-1) M .
$$

In case the inflation-modified rate of return and the annual cost escalation rate $r_{e q}$ of the equipment vary from year to year during the project period, $P E F_{e q}$ is given by:

$$
P E F_{e q}=C_{e q, 0}\left(1+\sum_{i=2}^{R}\left(\frac{p}{f}\right)_{X_{i}}^{i_{f}} \prod_{j=1}^{X_{i}}\left(1+r_{e q, j}\right)\right) .
$$

The sum in parenthesis will vanish if the first item purchased is used over the entire project duration.

On the calculation of the salvage of the equipment, let $q_{f}$ denote the estimated remaining value in percentage of the first costs of the equipment after it operates over the expected lifetime. Assuming the value of equipment decreases linearly with time, the remaining value $q_{i}$ of the $i$-th item purchased $(i=1, \ldots, R)$ after it operates over its actual lifetime with respect to the project duration is given by:

$$
q_{i}=1-\frac{1-q_{f}}{M} \min (M, Z-M(i-1)),
$$

The year $Y_{i}$ of the decommissioning of the $i$-th item should correspond to the minimum between the year of the purchase of the next item or the project end:

$$
Y_{i}=\min (i M, Z), \quad \text { with } i=1, \ldots, R .
$$

By taking into account all the items to be purchased during the project lifetime and the annual increase on the first costs, the present equivalent of the salvage value of the equipment is given by:

$$
P E V_{e q}=C_{e q, 0}\left(\left(\frac{p}{f}\right)_{Y_{1}}^{i_{f}} q_{1}+\sum_{i=2}^{R}\left(\frac{p}{f}\right)_{Y_{i}}^{i_{f}} q_{i} \prod_{j=1}^{X_{i}}\left(1+r_{e q, j}\right)\right) .
$$

The sum in parenthesis will vanish if the first item purchased is used over the whole project duration.

In order to formulate the present equivalent of depreciation under varying inflation-modified rate of return, let $\left(\frac{f}{a}\right)_{M, X_{i}}^{i_{f}}$ denote the series compound amount factor expressed as follows:

$$
\left(\frac{f}{a}\right)_{M, X_{i}}^{i_{f}}=1+\sum_{i=2}^{M} \prod_{j=i}^{M}\left(1+i_{f, X_{i}+j}\right) .
$$

This factor converts a uniform series of annual depreciation to a future value for an item purchased at the year $X_{i}$ of the project and operated over $M$ years

The present equivalent of depreciation of an equipment is obtained by summing up the present equivalent of the future value of the annual depreciation of all the items, taking into account the annual cost escalation 
rate of the equipment. Adopting the straight-line depreciation method and writing off the depreciation charges remaining at the end of the project, this results in:

$$
\begin{aligned}
P E D_{e q}= & \frac{C_{e q, 0}}{M}\left(\sum_{i=1}^{R-1} \prod_{j=1}^{X_{i}}\left(1+r_{e q, j}\right)\left(\frac{p}{f}\right)_{X_{i}+M}^{i_{f}}\left(\frac{f}{a}\right)_{M, X_{i}}^{i_{f}}+\prod_{j=1}^{S_{R}}\left(1+r_{e q, j}\right)\left(\frac{p}{f}\right)_{Z}^{i_{f}}\left(\frac{f}{a}\right)_{Z-S_{R}, S_{R}}^{i_{f}}\right. \\
& \left.+(Q M-Z) \prod_{j=1}^{S_{R}}\left(1+r_{e q, j}\right)\left(\frac{p}{f}\right)_{Z}^{i_{f}}\right) .
\end{aligned}
$$

In case a unique item operates over the entire project duration, that is $R=1, P E D_{e q}$ is simplified as follows

$$
P E D_{e q}=\frac{C_{e q, 0}}{M}\left(\left(\frac{p}{f}\right)_{Z}^{i_{f}}\left(\frac{f}{a}\right)_{Z, 0}^{i_{f}}+(M-Z)\left(\frac{p}{f}\right)_{Z}^{i_{f}}\right) .
$$

Keeping $C_{e q, 0}$ factorized, the successive substitution of (A.9), (A.10) and (A.11) or (A.12) into (A.8), and of (A.8) into (A.7) allows to determine $k_{e q}$ indicated in (A.6).

\section{Appendix B. Optimization program for multi-drive belt conveyors}

The optimization problem that minimizes the life cycle cost of a multi-drive belt conveyor equipped with $N$ intermediate dive stations is given by 


$$
\begin{aligned}
& \min _{X} A_{\text {energy }}+A_{\text {belt }}+2 \sum_{i=1}^{N+1} A_{\text {motor }, i}+2 \sum_{i=1}^{N+1} A_{\text {gearreducer }, i}+A_{\text {carryidler }}+A_{\text {returnidler }} \\
& \text { s.t. } \rho A_{t h} v=Q \text {, } \\
& \sum_{k=1,3, \ldots}^{N_{o}} L_{o, k}-\sum_{i=1}^{N} D_{t r, i}=L / \cos \delta \\
& 2 \sum_{i=1}^{N+1} P_{i} \eta_{\text {gear }, i}-v F_{W}=0, \\
& \frac{2 T_{i} v}{D_{t r, i}}=\eta_{\text {gear }, i} P_{i}, \quad i=1, \ldots, N+1, \\
& F_{T 2, j} \geq \frac{2 C_{w, j} P_{j} \eta_{g e a r, j}}{v}, \quad j=1, \ldots, N+1, \\
& F_{0} \geq \frac{g\left(m_{L}^{\prime}+m_{G}^{\prime}\right) l_{o}}{8 h_{r e l}}, \\
& F_{T 2, j} \geq \frac{g\left(m_{L}^{\prime}+m_{G}^{\prime}\right) l_{o}}{8 h_{r e l}}, \quad j=1, \ldots, N, \\
& F_{T D} \geq \frac{g m_{G}^{\prime} l_{u}}{8 h_{r e l}}, \\
& F_{T 1, i}=F_{T 1,1} \text {, } \\
& \frac{k_{t, r e l} k_{N}}{S_{0} S_{1}} \geq \frac{F_{T 1,1}}{B}, \\
& D_{t r, j} \geq c_{T r} d_{G k}, \quad j=1, \ldots, N+1, \\
& S_{f} B_{f} L_{f} F_{s, o} \leq F_{\max , o}, \\
& S_{f} B_{f} C_{f} F_{s, u} \leq F_{\max , u}, \\
& P_{i}=P_{1} \text {, } \\
& T_{i}=T_{1}, \\
& D_{t r, i}=D_{t r, 1} \text {, } \\
& \alpha_{i}=\alpha_{1} \text {, } \\
& \frac{60 v}{\pi D_{o}} \leq 750 \\
& \frac{60 v}{\pi D_{u}} \leq 750,
\end{aligned}
$$

with the design parameters subject to the boundary limits

$$
\begin{aligned}
& 0 \leq P_{i} \leq P_{\text {max }}, \quad i=1, \ldots, N+1, \\
& 0 \leq T_{i} \leq T_{\max }, \quad i=1, \ldots, N+1, \\
& D_{t r, i} \in \mathfrak{D}_{t r}, \quad i=1, \ldots, N+1, \\
& \alpha_{\min } \leq \alpha_{i} \leq \alpha_{\max }, \quad i=1, \ldots, N+1, \\
& L_{\min } \leq L_{o, j} \leq L_{\max }, \quad j=1, \ldots, N_{o}, \\
& B \in \mathfrak{B}, \\
& 0 \leq v \leq v_{\text {max }}, \\
& 0 \leq k_{N} \leq k_{N, \text { max }}, \\
& 0 \leq F_{T U} \leq F_{T U, \text { max }},
\end{aligned}
$$




$$
\begin{aligned}
& l_{o, \min } \leq l_{o} \leq l_{o, \max }, \\
& l_{u, \min } \leq l_{u} \leq l_{u, \max }, \\
& D_{o} \in \mathfrak{D}, \\
& D_{u} \in \mathfrak{D}, \\
& d_{o} \in \mathfrak{d}, \\
& d_{u} \in \mathfrak{d} .
\end{aligned}
$$

\section{Acknowledgements}

The authors acknowledge the support for this work provided by the National Hub for Energy Efficiency and Demand Side Management and the National Research Foundation of South Africa under grant unique number 105047.

\section{References}

[1] Eskom, Integrated Report 2017 (March 2017).

[2] Eskom, The Energy Efficiency series. Towards an energy efficient mining sector (February 2010). URL http://www.eskom.co.za/sites/idm/Documents/121040ESKD_Mining_Brochure_paths.pdf

[3] S. Zhang, X. Xia, Optimal control of operation efficiency of belt conveyor systems, Applied Energy 87 (6) (2010) $1929-1937$.

[4] A. Tapp, Conveying technology-energy saving troughing idler technology, Bulk Solids Handling 20 (4) (2000) $437-449$.

[5] P. Darling (Ed.), SME mining engineering handbook, 3rd Edition, Society for Mining Metallurgy \& Exploration, Englewood, 2011.

[6] A. Dalgleish, L. Grobler, Measurement and verification of a motor sequencing controller on a conveyor belt, Energy 28 (9) (2003) $913-927$.

[7] P. Bindzár, D. Malindžák, Number of conveyor belts optimization regarding to its type and logistical parameters in mining industry, Acta Montanistica Slovaca 13 (4) (2008) 524-531.

[8] X. Xia, J. Zhang, Energy efficiency and control systems-from a POET perspective, in: Conference on Control Methodologies and Technology for Energy Efficiency, Vilamoura, Portugal, 2010, pp. 225-260.

[9] X. Xia, J. Zhang, Modelling and control of heavy-haul trains, IEEE Control Systems Magazine 31 (4) (2011) $18-31$.

[10] X. Xia, L. Zhang, Industrial energy systems in view of energy efficiency and operation control, Annual Reviews in Control 42 (2016) 299-308.

[11] Association for Rubber Products Manufacturers Inc., Indianapolis, US, Conveyor and elevator belt handbook (2011).

[12] R. Dejchanchaiwong, A. Arkasuwan, A. Kumar, P. Tekasakul, Mathematical modeling and performance investigation of mixed-mode and indirect solar dryers for natural rubber sheet drying, Energy for Sustainable Development 34 (2016) 44-53.

[13] A. T. de Almeida, P. Fonseca, P. Bertoldi, Energy-efficient motor systems in the industrial and in the services sectors in the European Union: Characterisation, potentials, barriers and policies, Energy 28 (7) (2003) 673-690.

[14] D. V. Petrović, M. Tanasijević, V. Milić, N. Lilić, S. Stojadinović, I. Svrkota, Risk assessment model of mining equipment failure based on fuzzy logic, Expert Systems with Applications 41 (18) (2014) 8157-8164.

[15] D. Mazurkiewicz, Maintenance of belt conveyors using an expert system based on fuzzy logic, Archives of Civil and Mechanical Engineering 15 (2) (2015) 412-418.

[16] A. Middelberg, J. Zhang, X. Xia, An optimal control model for load shifting - with application in the energy management of a colliery, Applied Energy 86 (7-8) (2009) 1266-1273.

[17] B. Jeftenić, I. Mihailović, M. Bebić, L. Ristić, D. Jevtić, N. Rašić, S. Štatkić, Energy efficiency in transportation of bulk material with frequency controlled drives, in: 14th International Conference on Power Electronics and Motion Control, Ohrid, Macedonia, 2010, pp. 107-113.

[18] L. B. Ristic, M. Z. Bebic, D. S. Jevtic, I. D. Mihailovic, S. Z. Statkic, N. T. Rasic, B. I. Jeftenić, Fuzzy speed control of belt conveyor system to improve energy efficiency, in: 15th International Conference on Power Electronics and Motion Control, Novi Sad, Serbia, 2012, pp. 1-7.

[19] D. He, Y. Pang, G. Lodewijks, Green operations of belt conveyors by means of speed control, Applied Energy 188 (2017) $330-341$.

[20] J. Luo, Y. Shen, Energy efficiency optimization of belt conveyor for material scheduling problem, in: 2015 IEEE International Conference Information and Automation, Lijiang, China, 2015, pp. 122-127.

[21] J. Luo, W. Huang, S. Zhang, Energy cost optimal operation of belt conveyors using model predictive control methodology, Journal of Cleaner Production 105 (2015) 196-205.

[22] T. Mathaba, X. Xia, J. Zhang, Optimal scheduling of conveyor belt systems under critical peak pricing, in: 10th International Power and Energy Conference, Ho Chi Minh City, Vietnam, 2012, pp. 315-320.

[23] S. Windmann, O. Niggemann, H. Stichweh, Energy efficiency optimization by automatic coordination of motor speeds in conveying systems, in: 2015 IEEE International Conference on Industrial Technology, Seville, Spain, 2015, pp. 731-737. 
[24] J. Schützhold, K. Benath, V. Müller, W. Hofmann, Design criteria for energy efficient belt conveyor drives, in: 2014 International Symposium on Power Electronics, Electrical Drives, Automation and Motion, Ischia, Italy, 2014, pp. 12561263.

[25] A. V. Reicks, Belt conveyor idler roll behaviors, in: M. A. Alspaugh (Ed.), Bulk Material Handling by Conveyor Belt 7, Vol. 7, Society for Mining Metallurgy \& Exploration, Englewood, 2008, pp. 35-40.

[26] A. E. Maton, The effects of idler selection on conveyor belt power consumption, Bulk Solids Handling 22 (1) (2003) 46-49.

[27] G. Lodewijks, Determination of rolling resistance of belt conveyors using rubber data: Fact or fiction?, Bulk Solids Handling 23 (6) (2003) 384-391.

[28] A. V. Reicks, T. J. Rudolphi, C. A. Wheeler, A comparison of calculated and measured indentation losses in rubber belt covers, Bulk Solids Handling 32 (3) (2012) 52-57.

[29] C. Wheeler, Indentation rolling resistance of belt conveyors-a finite element solution, Bulk Solids Handling 26 (1) (2006) $40-43$.

[30] A. Roberts, Economic analysis in the optimization of belt conveyor systems, in: Proceedings of Beltcon 1 Conference, Johannesburg, South Africa, 1981, pp. 1-33.

[31] C. A. Wheeler, Evolutionary belt conveyor design: Optimizing costs, in: M. A. Alspaugh (Ed.), Bulk Material Handling by Conveyor Belt 7, Vol. 7, Society for Mining Metallurgy \& Exploration, Englewood, 2008, pp. 3-11.

[32] M. A. Alspaugh, The evolution of intermediate driven belt conveyor technology, Bulk Solids Handling 23 (3) (2003) 168-172.

[33] DIN 22101, Continuous mechanical handing equipment - Belt conveyors with carrying idlers - Calculation of operating power and tensile force (2011).

[34] A. J. G. Nuttall, Design aspects of multiple driven belt conveyors, Ph.D. thesis, TU Delft, Delft University of Technology (2007).

[35] Conveyor Equipment Manufacturers Assoc., Naples, US, Belt conveyors for bulk materials, 5th Edition (1997).

[36] A. Frittella, S. Curry, Conveyor idlers - sans 1313 and selection procedures, in: Proceedings of Beltcon 15 Conference, Johannesburg, South Africa, 2009, pp. 1-14.

[37] Handling Sandvik Materials, Sandviken, Sweden, Design criteria for product selection - Pulleys, idlers, and materials handing systems (2013).

[38] US Bureau of Economic Analysis, BEA Rates of depreciation, service lives, declining-balance rates, and Hulten-Wykoff categories.

URL https://bea.gov/scb/account_articles/national/wlth2594/tableC.htm

[39] M. S. Masaki, A cost-effective design approach for multiple drive belt conveyor systems, Masters' thesis, University of Pretoria, South Africa (May 2017).

[40] M. Schlüter, J. A. Egea, J. R. Banga, Extended ant colony optimization for non-convex mixed integer nonlinear programming, Computers \& Operations Research 36 (7) (2009) 2217-2229.

[41] T. Eschenbach, Engineering economy: applying theory to practice, 2nd Edition, Oxford University Press, New York, 2003. 